\title{
COMPARATIVE SLOW BEND AND IMPACT NOTCHED BAR TESTS ON SOME METALS
}

\author{
By S. N. Petrenko
}

ABSTRACT

Comparative impact and slow-bend tests on notched bars were made on some nonferrous alloys and steels in order to determine whether the slow-bend test may be used as a substitute for, or as a useful addition to, the impact test. The tests were made in an Izod pendulum type impact machine of 120 foot-pound capacity and a Humfrey slow-bend machine of about 100 foot-pound capacity, on the cantilever beam type specimens, having 10 by $10 \mathrm{~mm}$ section.

The effect of the shape of notch on the impact and on the slow-bend values was also studied. The slow-bend test gave values lower than the impact for nonferrous materials and higher than the impact for steels.

Wherever the variation of the notched bar values is present in the specimens made of the same material, whether this variation is due to the shape of notch or to its position in respect to the rolling direction, or to the variation in the notched bar properties of a material, the slow-bend test gives results comparable with those of the impact test, but it is less responsive to these variations than the impact test. By means of a bending moment diagram the slow-bend test gives some values which are related to the tensile yield point and to the tensile strength of the materials.

It is, however, less convenient than the impact for the ordinary routine practice.

The metallographic examination has shown that the variation in the individual values of notched bar tests made on the same sample and under identical conditions can, in many cases, be directly accounted for by the structural condition of metal and by the presence of inclusions instead of being considered as test errors which are beyond the control of operator.

An empirical formula gives the slow-bend or the impact value as a sum of two terms, one of which is proportional to the radius of the notch and the other to the square of the net thickness of the specimen.

For brittle materials the impact and the slow-bend values are greatly affected by the radius of the notch but are little affected by the net thickness of the specimen. For tough materials the opposite is true.

\section{CONTENTS}

I. Introduction

II Scope of the work

III. Acknowledgment.

IV. Testing machines

V. Interpretation of a slow-bend diagram

VI. Sources of errors in testing machines

1. Impact machine.

2. Slow-bend machine... 321

VII. Specimens 
VIII. Materials

IX. Results of tests

X. Metallographic examination

1. Macrostructure.

2. Microstructure

(a) Ferrous metals _......... 329

(b) Nonferrous metals

(1) Duralumin

(2) Aluminum bronze

(3) Phosphor bronze.

(4) Nickel silver _.

(5) Brass........ 330

XI. Discussion of results

1. General relation between the impact and the slow-bend values.

2. Variation along the length of a bar of the impact and of the

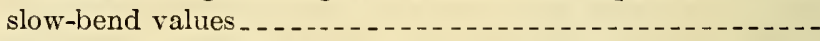

3. Difference in the impact and the slow-bend values between the specimens having notches in the plane of rolling and those with the notches at right angle to the plane of rolling

4. Relative efficiency of the different notches in detecting differences in the notched-bar resistance of the materials...

5. Effect of varying the radius of the notch on the energy ---

6. Effect of the depth of the notch on the energy

XII. Empirical formula for absorbed energy

XIII. Conclusions...... 342

1. Machine

2. Effect of speed

3. Fracture of specimen

4. Notch

5. Empirical formula

XIV. Bibliography $\ldots \ldots$

\section{INTRODUCTION}

Some machinery parts, as well as parts of some larger engineering structures, are very often subjected to sudden shocks which may stress the material above the ordinar stresses for which the part is designed.

Experience teaches us that the effect of such shocks are more severe when a structural member has sharp reentrant angles. In the immediate vicinity of such places the stresses may rise far above those for which the member is designed. The abnormally high stresses produced by a suddenly applied force are particularly dangerous in a material which has not been correctly heat treated, and which, as the result, has a peculiar property of shock brittleness. In this case the ordinary static tests can not reveal the inherent weakness of such material. Hence, the necessity of an impact test. The most convenient of such tests, and one in which the material approximates 
the most dangerous possible conditions, is a transverse impact test on notched specimens. In this test the total energy absorbed by a standard specimen is measured. Due to the extremely short period of time during which the deformation occurs, it is inconvenient to obtain any other information in an impact test. It has been claimed, howerer, that a slow-bend test on a notched specimen may give the same information that an impact test gives and, moreover, it may show some other properties of material which can not be easily shown in an impact test. Among these properties, for example, is the value of bending moment corresponding to any given angle of bend.

\section{SCOPE OF THE WORK}

The relation between the manner in which the force is applied and the energy absorbed by a notched specimen has been the subject of a number of investigations. Most of these investigations were conducted on ferrous alloys. The list of these works is given in the bibliography (see p. 345 ). In order to determine whether a slow-bend test may be used as a substitute for an impact test or as a valuable addition to it, and in order to determine also its practicability, the Bureau of Standards has made parallel impact and slow-bend tests on some materials, mostly nonferrous alloys. The effect of the shape of notch on the impact and on the slow-bend values has also been studied to determine whether this effect may be expressed by a definite law.

In Series I of these tests a comparison was made of the impact and of the slow-bend values obtained from a large number of tests (in Table 2 and in other places materials used in this series are marked $\mathrm{A}$ ).

In Series II tests the effect of the shape of the notch on the impact and on the slow-bend values was studied.

\section{ACKNOWLEDGMENT}

The materials used in these tests were given by the following manufacturers:

1. American Brass Co.

2. International Nickel Co.

3. Aluminum Co. of America.

4. American Rolling Mills Co.

5. Carpenter Steel Co.

6. Bausch Machine Tool Co.

7. Reading Iron Co.

The writer is also indebted to Samuel Epstein for a metallographic examination of the materials used in these tests. His report is giren in full in Section $\mathbf{X}$ of this paper. 


\section{TESTING MACHINES}

The Humfrey slow-bend machine, which was used in this investigation, is shown in Figure 1. The bending moment is applied to the specimen, which is held in a vise at $H$, by means of a flexible $\operatorname{arm} A$. Parrallel to this arm and immediately above it is a rigid $\operatorname{arm} B$, along which slides a pencil carrier, drawn by a wire, the other end of which is fastened to the post $C$. The displacements of the pencil along the arm $B$ are proportional to the angle through which the specimen is bent. The flexible arm carries a plate $D$ for the paper on which the bending moment diagram is drawn.

As the deflection of arm $A$ is proportional to the bending moment, the ordinates of the diagram measure the bending moment. Thus, the area of the diagram represents the energy absorbed by the specimen. Since it would be inconvenient to measure the energy from this diagram owing to the fact that the ordinates are not straight lines and the scale for the ordinates changes with the angle of bending (see fig. 3), a mechanical integrator $E$ is used to record the energy absorbed by the specimen at any instant during the test. The capacity of this machine is about 100 foot-pounds and the maximum angle through which a specimen is bent is about $35^{\circ}$. The rate of bending in all these tests was about $2^{\circ}$ per second.

The impact machine, which is shown in Figure 2, was an Izod pendulum type machine having a capacity of 120 foot-pounds. The striking velocity of the hammer was 12.44 feet per second. In this machine a specimen is bent through an angle of about $60^{\circ}$.

The Izod impact machine was chosen for these comparative tests as this machine requires the same size of specimen as the slow-bend machine. In each of these machines the specimen is fixed at one end and the force applied at the other end.

\section{INTERPRETATION OF A SLOW-BEND DIAGRAM}

Typical diagrams are shown in Figure 3. The diagrams obtained in slow-bend tests belong to one of the two types shown in Figure 4, type 1 representing ductile and type 2 brittle materials.

Owing to the presence of the notch in the specimen and the resulting high concentration of stresses, a slow-bend diagram is not directly comparable with a diagram which may be obtained in a transverse or tensile test. However, some values given by the slow-bend diagram may be correlated with certain tensile or transverse values.

It is obvious that these bending diagrams are similar to the stressdeformation diagrams for tensile or transverse tests. The portion $A B$ of the curve corresponds to the elastic deformation of the specimen, and near the point $B$ plastic deformation begins to take place; that is, the specimen remains bent when the bending moment is removed. 
Technologic Papers of the Bureau of Standards, Vol. 19

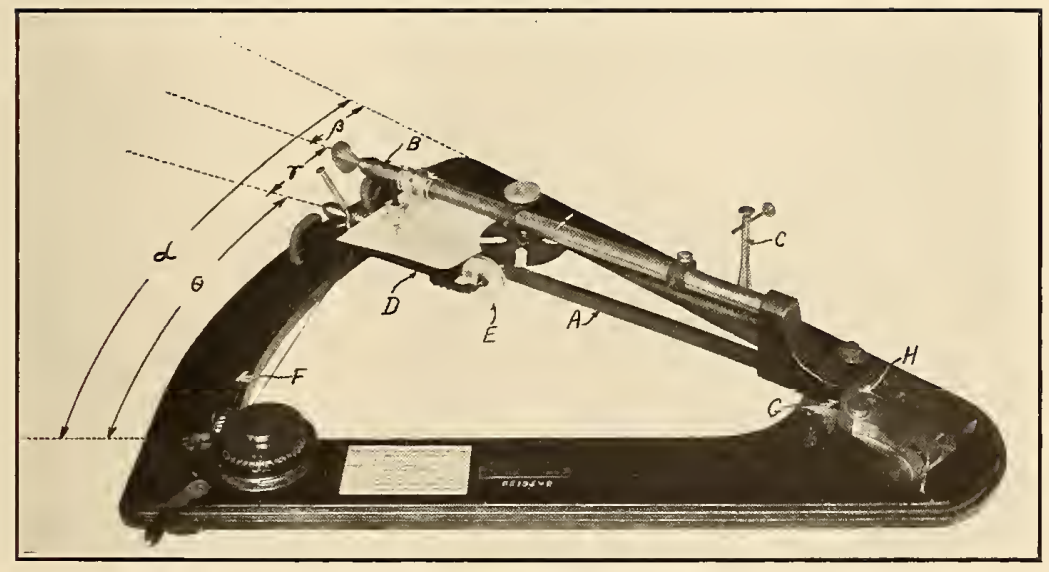

FIG. 1.-Slow-bend machine 
Technologic Papers of the Bureau of Standards, Vol. 19

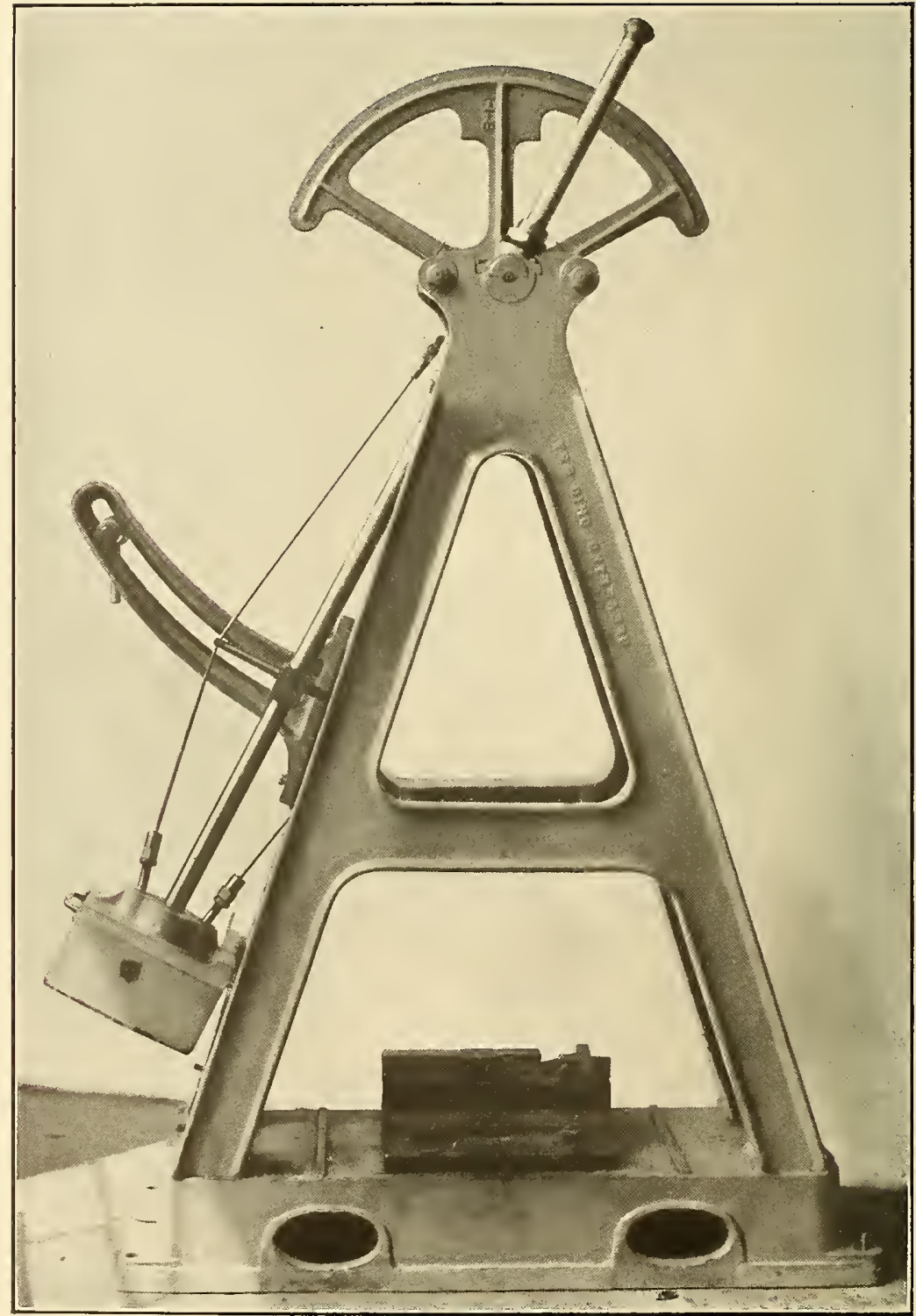

FIG. 2.-Impact machine 


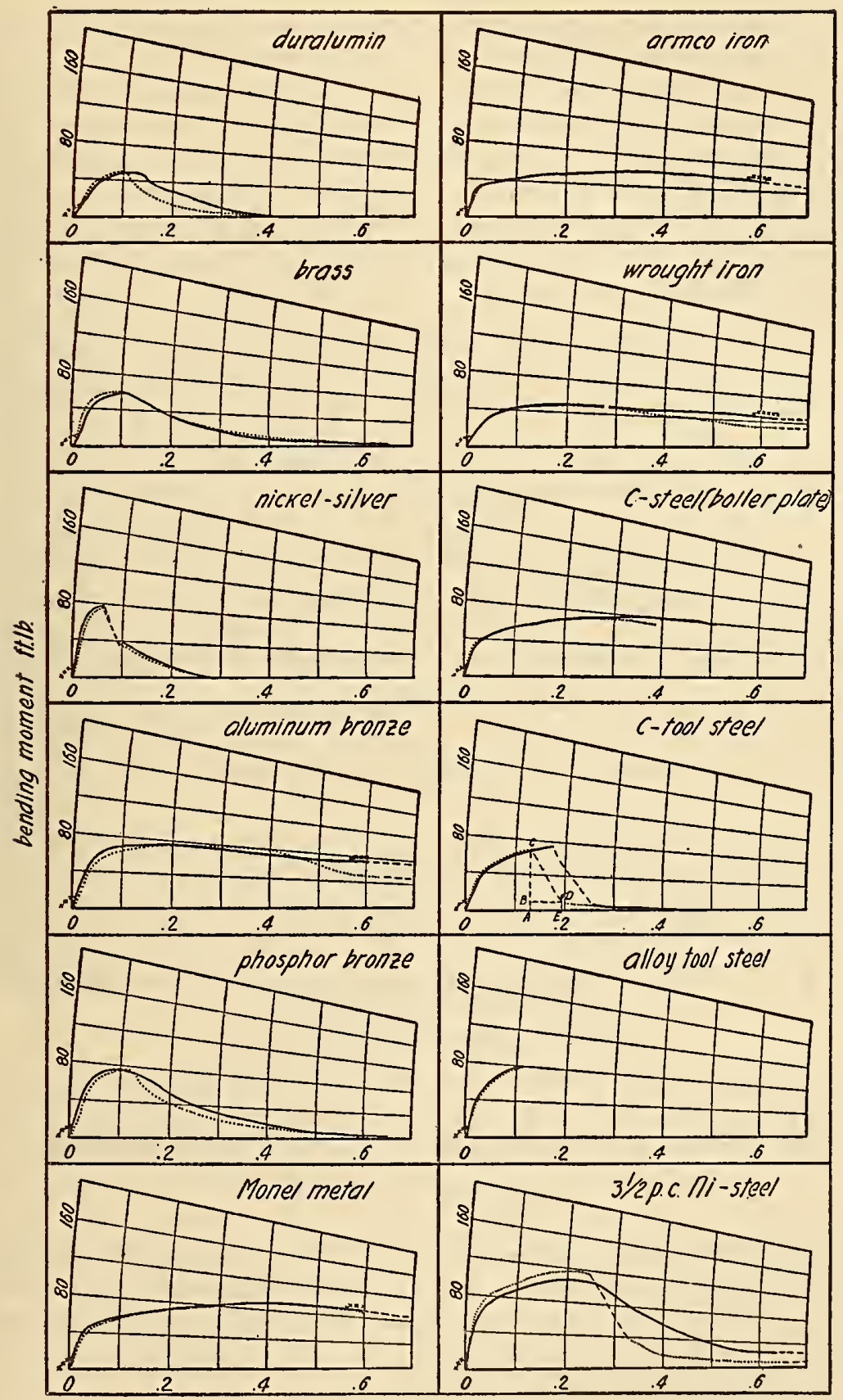

angle of bend radians

FIG. 3.-Typical slow-bend diagrams for "standard" notch

All the specimens were cut along the direction of rolling.

Specimens having the notch in the plane of rolling and at right angle to the direction of rolling.

Specimcns having the notch in the plane of rolling and at right angle to the direction of rolling.
Specimens having the notch at right angle to the plane of rolling.
Crosses at the beginning and at the cnd of a diagram indicate errors of the machine descrlbed in VI, 3 (d). The dash lines indicate tho displacement of pencil at a sudden break of a specimen. The involved error is described in VI, 2, (e). 
The portion of the diagram $B C$ corresponds to the period of plastic deformation of the specimen. The resistance of the specimen during this period changes but little. Soon after the maximum bending moment is reached the resistance of the specimen begins to drop off more or less rapidly. It is accompanied by the appearance of a crack or cracks at the bottom of the notch. The brittle materials are characterized by a very rapid extension of crack through the body of the specimen, while in ductile materials the cracks penetrate the specimen gradually as the angle of bend increases.

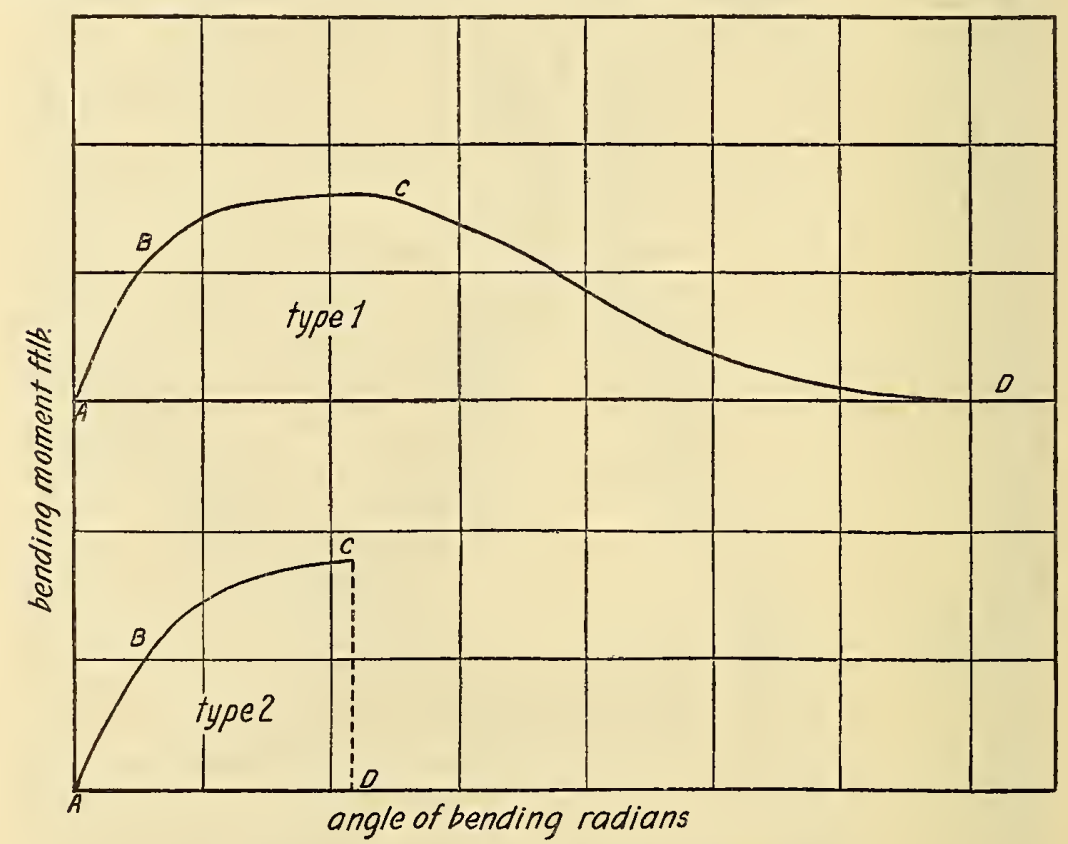

Fig. 4.-Two types of slow-bend diagrams

Type 1 represents the ductile materials. Type 2 represents the brittle materials.

\section{SOURCES OF ERROR IN TESTING MACHINES \\ 1. IMPACT MACHINE}

(a) Errors which are due chiefly to the friction between the hammer and specimen, if the latter is not entirely broken, and to the indentation made in the specimen by the striking edge of the hammer. The magnitude of these errors as roughly determined on some of the tough materials is given in Table 1. 
TABLE 1.-The approximate loss of energy due to the friction between the hammer and the specimen and to the indentation made by the striking edge of the hammer

[All values determined for standard notch]

\begin{tabular}{|c|c|c|}
\hline Material & $\begin{array}{l}\text { The loss } \\
\text { of energy } \\
\text { due to } \\
\text { friction } 1\end{array}$ & $\begin{array}{l}\text { The loss } \\
\text { of energy } \\
\text { due to } \\
\text { indenta- } \\
\text { tation }\end{array}$ \\
\hline $\begin{array}{l}\text { MIonel metal } \\
\text { Aluminum hronze }\end{array}$ & $\begin{array}{r}F t .-l b . \\
4 \\
2 \\
1.5\end{array}$ & $\begin{array}{l}\text { Ft. }-l b \text {. } \\
\text { About } 1.0 \\
\text { Do. } \\
\text { Do. }\end{array}$ \\
\hline
\end{tabular}

1 Determined on a specimen after it had heen tested and left in the machine.

3 Determined hy dropping a weight from a height necessary to produce indentation equal to that produced hy the striking edge of the hammer.

The sum of these errors is negligible in most cases, but, as the above table shows, may be as high as 5 per cent of the total energy for tough materials. ${ }^{1}$

A protector made of hard steel, similar to that used in the impact tests of wood, might diminish this part of the lost energy.

(b) Another source of error is the dissipation of impact energy through vibrations in the machine. This subject was discussed by R. Southwell, ${ }^{2}$ who recommends that the pendulum be suspended by ropes to avoid the dissipation of energy. It is also believed that a part of the energy is dissipated through the vibrations of the specimen.

The appearance of the upper portion of some tough specimens, such as nickel steel and aluminum bronze, indicates that the initial blow of the hammer is followed by a succession of light blows which are due to the vibrations of specimen. The loss of energy due to these repeated blows is, however, very small.

\section{SLOW-BEND MACHINE}

(a) In the type of machine used in these tests the tension of a coil spring stretched between the end post $C$ and the integrator increases as the angle of bending increases, and the work, which is required to stretch the spring, is added to the reading of the integrator.

For the specimens which break at a comparatively small angle of bend, say, not more than $15^{\circ}$, this error may be disregarded; but for the larger angles of bend a correction ought to be made Its value may be found by determining the work of stretching the spring

1 As the terms "ductile," "hrittle," and "tough" are used often in this paper, they aro defined here. These definitions are taken from B. S. Circular No. 101, Physical Properties of Matcrials, 1924. Ductile materials are those which are capable of undergoing considerable permanent deformation while subjected to tensile stresses. Brittle materials are those which show little permanent deformation when stressed to rupture. Tough materials are those which will withstand heavy shocks or will ahsorb a large amount of energy.

${ }^{2}$ Note on the application of dimensional theory to notehed har impact tests, Aeronautical Resenreh Committee, Peports and Memoranda No. 732 (M.2), January, 1921. $34208^{\circ}-25-2$ 
with no specimen in place. In these tests it was about 1.5 footpound for the maximum angle of bend; that is, from about 1 per cent for tough materials like Monel metal and aluminum bronze to about 4 per cent for brass.

(b) The maximum angle through which the rigid arm $B$.(see fig. 1) may be rotated is $\alpha$. But in view of the deflection of the flexible arm $A$, the angle through which a specimen may be bent is less than $\alpha$. In a test, when the arm $A$ is brought to $F$ and angle $\theta$ becomes equal to zero, we have: $\alpha=\beta_{\max }+\gamma$. As the angle $\alpha$ is constant, it is evident that $\beta_{\max }$ depends upon $\gamma$. For materials which require large bending moments (large $\gamma$ ) $\beta$ max will be smaller than in the case of materials which require small bending moments. For most materials the value of $\beta_{\max }$ is from 30 to $40^{\circ}$. The angle of bend in the Izod impact machine is about $60^{\circ}$, and a correction ought to be made for slow-bend specimens, which are not entirely broken, in order to make the results obtained by two methods more nearly comparable. The energy for the angle of bend between that obtained in the slow-bend machine and $60^{\circ}$ was calculated and added to the slow-bend value.

This was done on the assumption that the energy absorbed in slow bend is proportional to the angle through which the specimen is bent.

This method was used because the diagrams of aluminum bronze, Armco iron, wrought iron, and Monel metal, to which it was applied, were of a horizontal type, as can be seen in Figure 3.

The values thus obtained were probably somewhat greater than the true values. The magnitude of this error is unknown, as it depends upon the resistance of the specimen between the angles of 35 and $60^{\circ}$. However, the great amount of resistance which the impact specimens still possessed after being bent through an angle of $60^{\circ}$ indicated that this error was relatively not very great. The rough determination of the residual resistance of the unbroken impact specimens showed that the error was of the magnitude of about 5 per cent.

It does not seem probable that a specimen which has retained a considerable amount of resistance after being bent through an angle of $35^{\circ}$ would lose its resistance entirely between 35 and $60^{\circ}$. If this occurred, the results of the impact and of the slow-bend test could not be compared.

(c) At the end of a test the end of the rigid arm may strike the point $G$ (see fig. 1) of the clamp holding the specimen, and this is recorded by the integrator and appears in the diagram as a sudden increase of bending moment (see fig. 3, diagrams of aluminum bronze, Monel metal, Armco iron, and wrought iron). The correction of this error is not necessary, as it is very small. 
(d) The slow-bend diagrams have in the beginning a small irregularity (shown in fig. 3 by the crosses), which manifests itself by the bend to the right and soon afterwards by the renewed increase of bending moment. This irregularity is due to an imperfect fitting of specimen to its seat in the rigid arm $B$ and being small does not need correction. The diagram, however, ought to be corrected by straightening the portion of it near $A$, as it was done in Figure 3.

(e) If a specimen fails suddenly, the pencil travels in an oblique direction, as if the resistance of the specimen was diminishing at a uniform rate. This may be true in a few individual cases. However, generally it is not so. It is not quite clear how the bending moment decreases with the increase of the angle of bend during this period, but it is certain that the energy absorbed by the specimen is less than that measured by the area $A C D E$ (see fig. 3, diagram for carbon tool steel) and greater than that measured by the area $A B D E$. The arerage of these two probably approximates the actual value. Evidently, the error in the value of the total energy can not exceed the amount represented by one-half of the area $B C D$.

The correction is to be applied to the reading of the integrator also, because the integrator fails to record the work done in the rapid displacement of the rigid arm, and its reading is therefore low.

The shock at failure usually throws the integrating wheel off the correct reading, and it is necessary to take a reading just before the failure of a brittle specimen.

\section{SPECIMENS}

In Figure 5 are shown the dimensions and the relative position of the impact and of the slow-bend specimens in a bar. The specimens

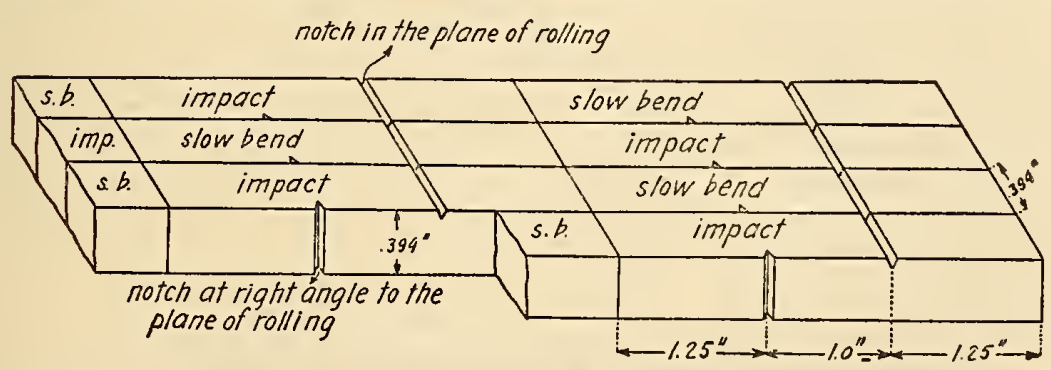

FIG. 5.-Location of the impact and of the slow-bend specimens in a plate

were of the cantilever type. They had notches alternately on the top of the specimen (in the plane of rolling and at right angle to the direction of rolling) and on the side (perpendicular to the plane of rolling).

For series 1 tests (see Table 3, materials A) all specimens had a standard $V$ notch 0.079 inch $(2 \mathrm{~mm})$ deep with a 0.01 -inch $(0.25-\mathrm{mm})$ 
radius at the bottom. For series 2 four different notches (see fig. 6) were used-"standard" V notch, "sharp" V notch, "round," and a "deep" notch.

The notches were so chosen as to have three values for comparison of the effect of the radius of notch and three values for the effect of the depth of notch.

The "standard" notch was that ordinarily used by this bureau for the Izod impact tests. The other three notches differed from the "standard" notch either in radius or in depth.
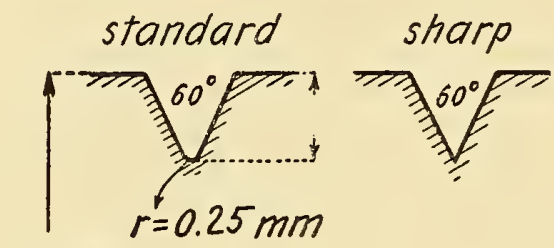

$10 \mathrm{~mm}$
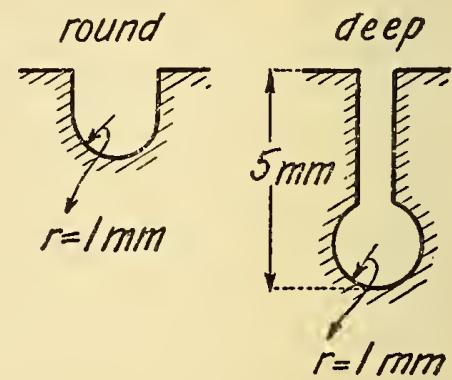

FIG. 6.-Types of notches used in the specimens of series ?

\section{IMATERIALS}

The following materials were used in this investigation:

(a) Duralumin.

(b) Brass.

(c) Phosphor bronze.

(d) Aluminum bronze.

(e) Nickel silver.

$(f)$ Monel metal.

(g) Armco iron.

(h) Wrought iron.

(i) 0.25 per cent carbon steel (boiler plate).

(j) Carbon tool steel.

(k) Alloy tool steel.

(l) $3 \frac{1}{2}$ per cent nickel steel.

The chemical composition, tensile properties, and hardness of these materials are given in Table 2. All these materials were supplied in the form of rectangular bars of about $2 \frac{1}{2}$ inches by $3 / 4$ inch in cross section, and they were tested as received from the mill. 


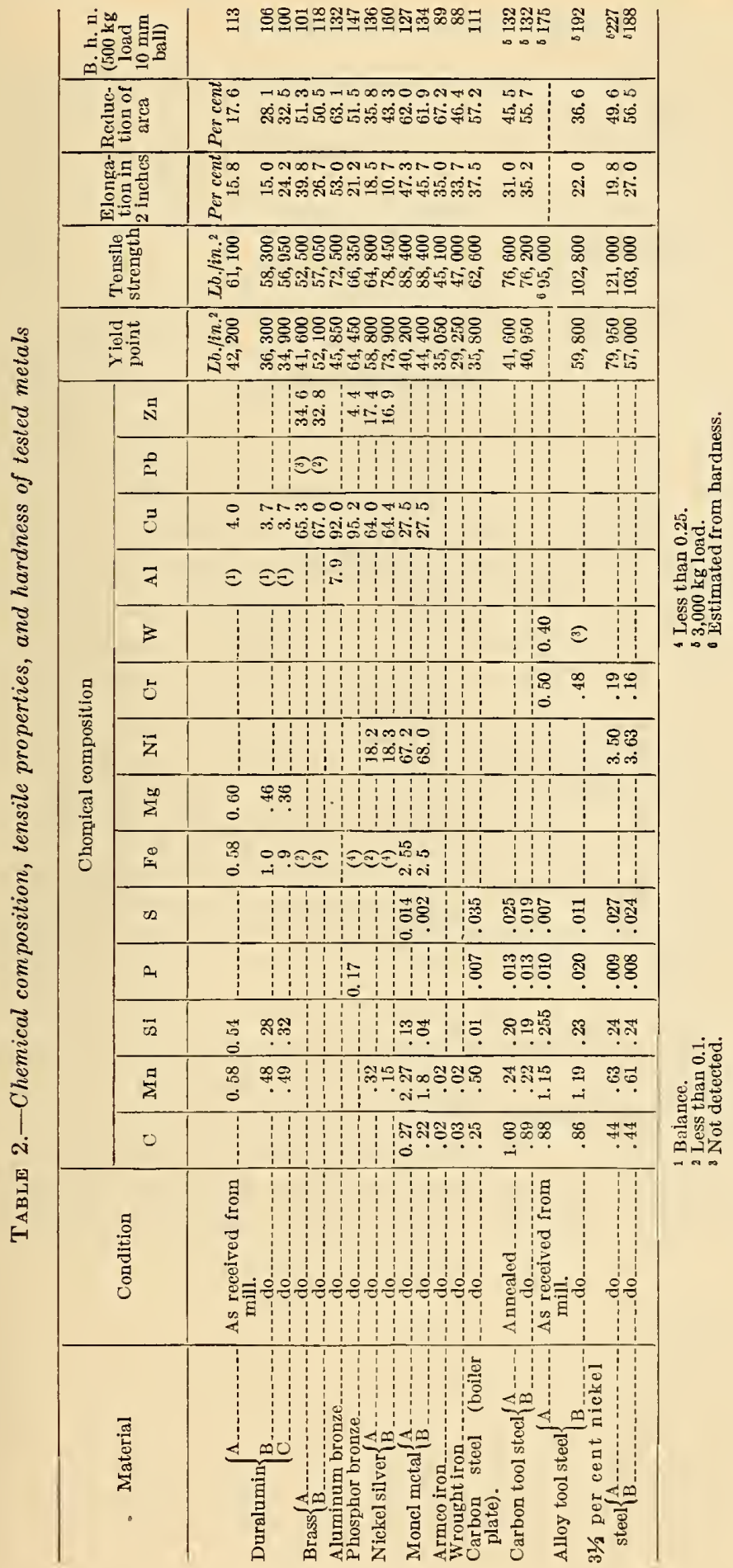




\section{RESULTS OF TESTS}

The results of notched-bar tests are given in Figure 7 and in Table 3. The impact and the slow-bend results are, in most cases, arerages of 10 or more determinations; those in other tests of two or more determinations.

In all cases of slow bend the specimen was bent through as great an angle as the testing machine would permit.

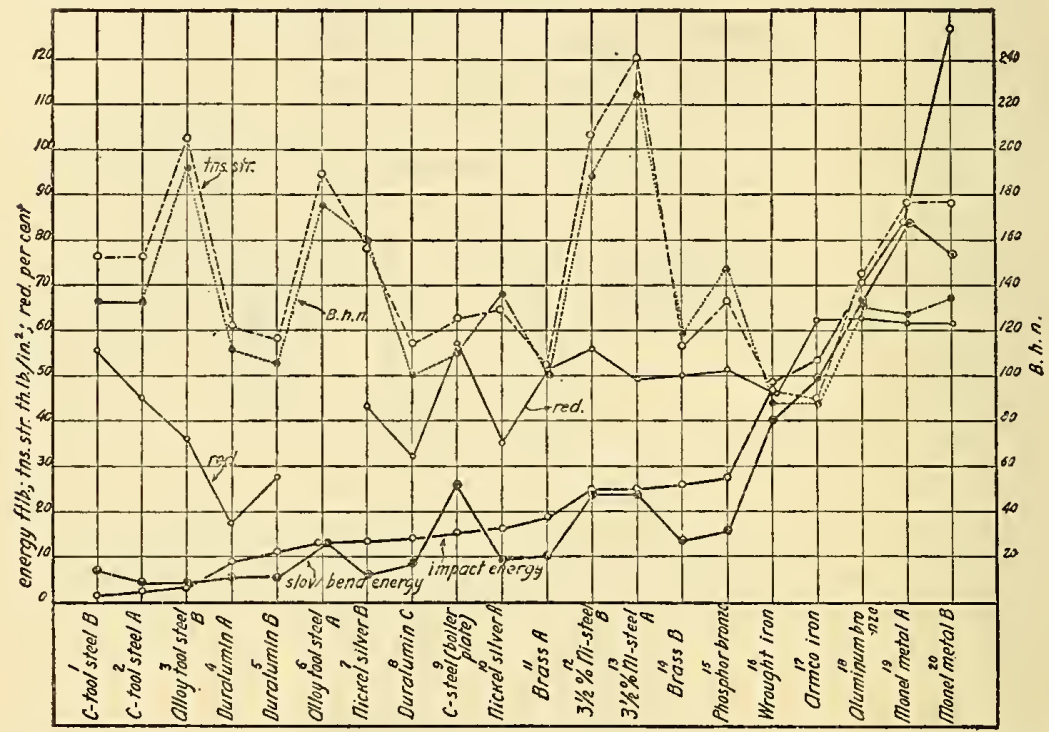

FIG. 7.-Impact and the slow-bend values compared with tensile properties of the materials. The impact and the slow-bend values are averages of all values obtained with the "siandard" notch

The angle through which a specimen was bent in impact machine is about $60^{\circ}$. In the slow-bend machine it was about $35^{\circ}$ (it varied somewhat with the bending moment as discussed in VI, 2, (b)).

The slow-bend values for the specimens which were not broken were corrected to give the energy for the angle of bend of $60^{\circ}$. The method of correction is described under "errors of testing machines" (VI, 2, (b)). 


\section{TABLE 3.-Summary of the results of tests}

[Materials marked $\mathrm{A}$ were used in series 1 tests and materials $\mathrm{B}$ and $\mathrm{C}$ in series 2. Each value is an average of at least four determinations]

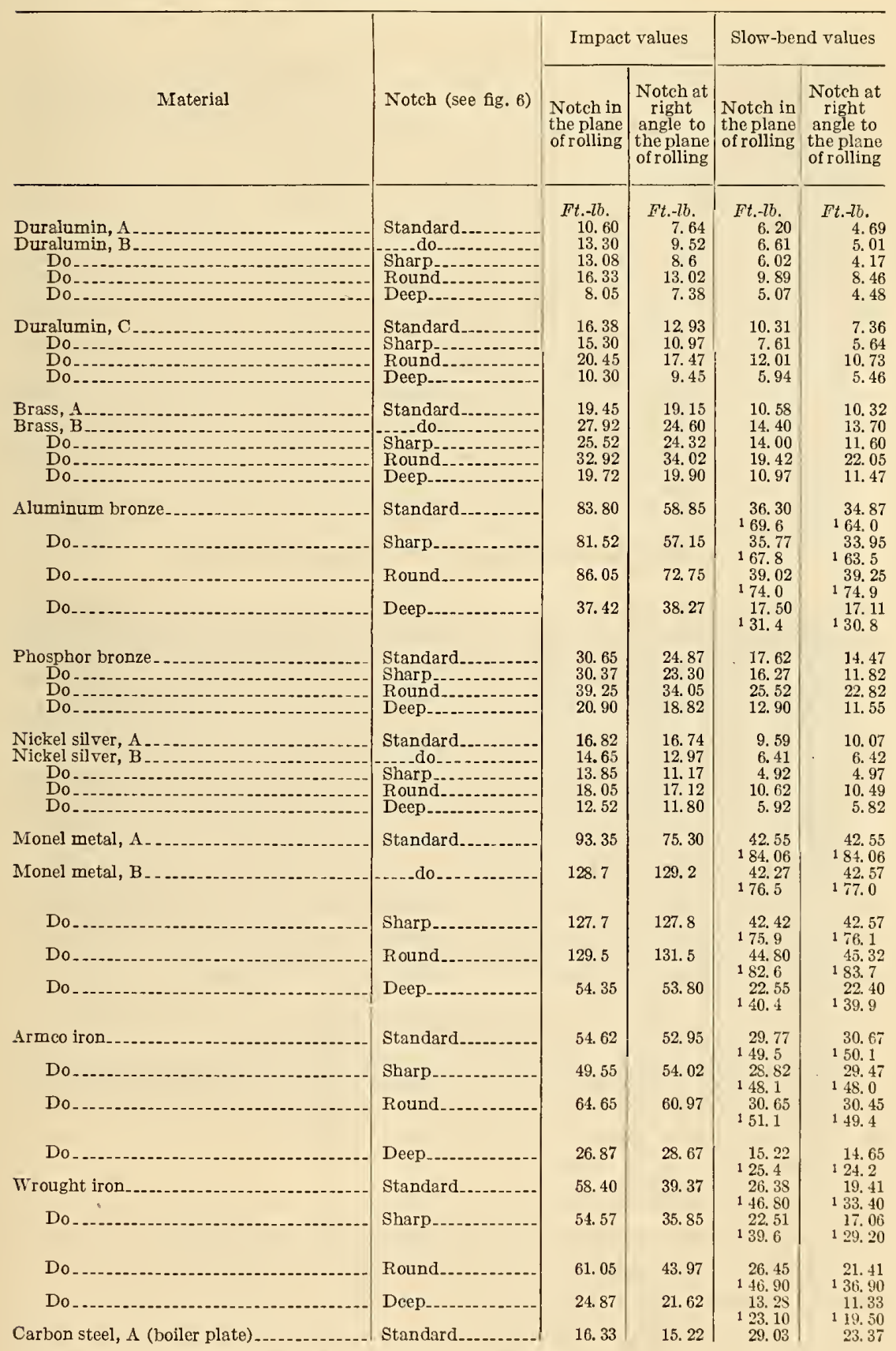

1 Values corrected for the same angle of bend as in Izod machine. 
TABLE 3.-Summary of the results of tests-Continued

\begin{tabular}{|c|c|c|c|c|c|}
\hline \multirow[b]{2}{*}{ Material } & \multirow[b]{2}{*}{ Notch (see fig. 6) } & \multicolumn{2}{|c|}{ Impact values } & \multicolumn{2}{|c|}{ Slow-bend values } \\
\hline & & $\begin{array}{l}\text { Notch in } \\
\text { the plane } \\
\text { of rolling }\end{array}$ & $\begin{array}{l}\text { Notch at } \\
\text { right } \\
\text { angle to } \\
\text { the plane } \\
\text { of rolling }\end{array}$ & $\begin{array}{l}\text { Notchin } \\
\text { the plane } \\
\text { of rolling }\end{array}$ & $\begin{array}{l}\text { Notch at } \\
\text { right } \\
\text { angle to } \\
\text { the plane } \\
\text { of rolling }\end{array}$ \\
\hline $\begin{array}{l}\text { Carbon tool steel, A (annealed) } \\
\text { Carbon tool steel, A (heat treated) } \\
\text { Carbon tool steel, } \mathrm{B} . \\
\text { Do }\end{array}$ & $\begin{array}{l}\text { Standard } \\
\text { Sharp }\end{array}$ & $\begin{aligned} F t .-2 b . \\
2.28 \\
5.08 \\
1.65 \\
1.08\end{aligned}$ & $\begin{array}{l}F t .2 l . \\
2.13 \\
5.08 \\
1.55 \\
1.02\end{array}$ & $\begin{aligned} F t .-2 b . \\
4.58 \\
8.02 \\
6.78 \\
3.95\end{aligned}$ & $\begin{aligned} \text { Ft. }-l b . \\
4.43 \\
8.30 \\
7.75 \\
\quad 3.94\end{aligned}$ \\
\hline 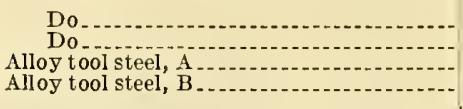 & 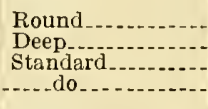 & $\begin{array}{r}6.45 \\
6.18 \\
13.33 \\
4.10\end{array}$ & $\begin{array}{r}7.23 \\
5.58 \\
13.18 \\
3.30\end{array}$ & $\begin{array}{r}21.93 \\
11.65 \\
13.60 \\
3.97\end{array}$ & $\begin{array}{r}22.54 \\
12.22 \\
13.55 \\
4.38\end{array}$ \\
\hline $\begin{array}{l}\text { Do } \\
\text { Do Do cent nickel steel, A. } \\
\text { D1/2 per }\end{array}$ & $\begin{array}{l}\text { Sharp } \\
\text { Round }{ }^{-} \\
\text {Deep } \\
\text { Standard. }\end{array}$ & $\begin{array}{r}2.30 \\
8.07 \\
7.77 \\
25.15\end{array}$ & $\begin{array}{r}2.67 \\
9.35 \\
7.25 \\
25.48\end{array}$ & $\begin{array}{r}2.56 \\
7.43 \\
5.57 \\
24.18\end{array}$ & $\begin{array}{r}2.45 \\
7.98 \\
5.10 \\
24.04\end{array}$ \\
\hline $\begin{array}{l}\text { 31/2 per cent nickel steel, B... } \\
\text { Do } \\
\text { Do } \\
\text { Do }\end{array}$ & $\begin{array}{l}\text { Sharp } \\
\text { Round } \\
\text { Deep................... }\end{array}$ & $\begin{array}{l}24.97 \\
19.50 \\
37.52 \\
24.02\end{array}$ & $\begin{array}{l}25.27 \\
17.67 \\
37.82 \\
25.27\end{array}$ & $\begin{array}{l}24.03 \\
18.87 \\
33.52 \\
16.37\end{array}$ & $\begin{array}{l}24.55 \\
19.47 \\
32.00 \\
17.12\end{array}$ \\
\hline
\end{tabular}

\section{METALLOGRAPHIC EXAMINATION ${ }^{3}$}

In comparing the results of the tests it was noted that although the results of the tensile and of the slow-bend tests on Monel metal $A$ and $B$ were practically the same, the results of the impact test showed much lower values for Monel metal A. As there was no apparent reason for this difference, the samples of Monel metal were examined microscopically and many more inclusions were found in Monel metal A than in B. This is shown in Figure 8. It will be noted that the grain size is about the same for both samples.

In order to determine, if possible, the relation between the structure of the metals and the results of notched-bar tests, particularly the impact test, specimens of other metals were examined microscopically. The results of this examination are given here.

\section{MACROSTRUCTURE}

Most of the metals used in this investigation show more or less pronounced fibrous structure which may be seen in the fractures of the notched bars shown in Figure 9 or which is revealed after a suitable etching as in Figure 10.

The necessary condition for the production of fibrous state is the presence of any consutuent distributed throughout the "ground mass" and which possesses decidedly different properties from the ground mass. Although in most materials it is the objectionable nonmetallic inclusions which play the most important part in causing

3 Samuel Epstein, associate physicist (Metallography). 
Technologic Papers of the Bureau of Standards, Vol. 19

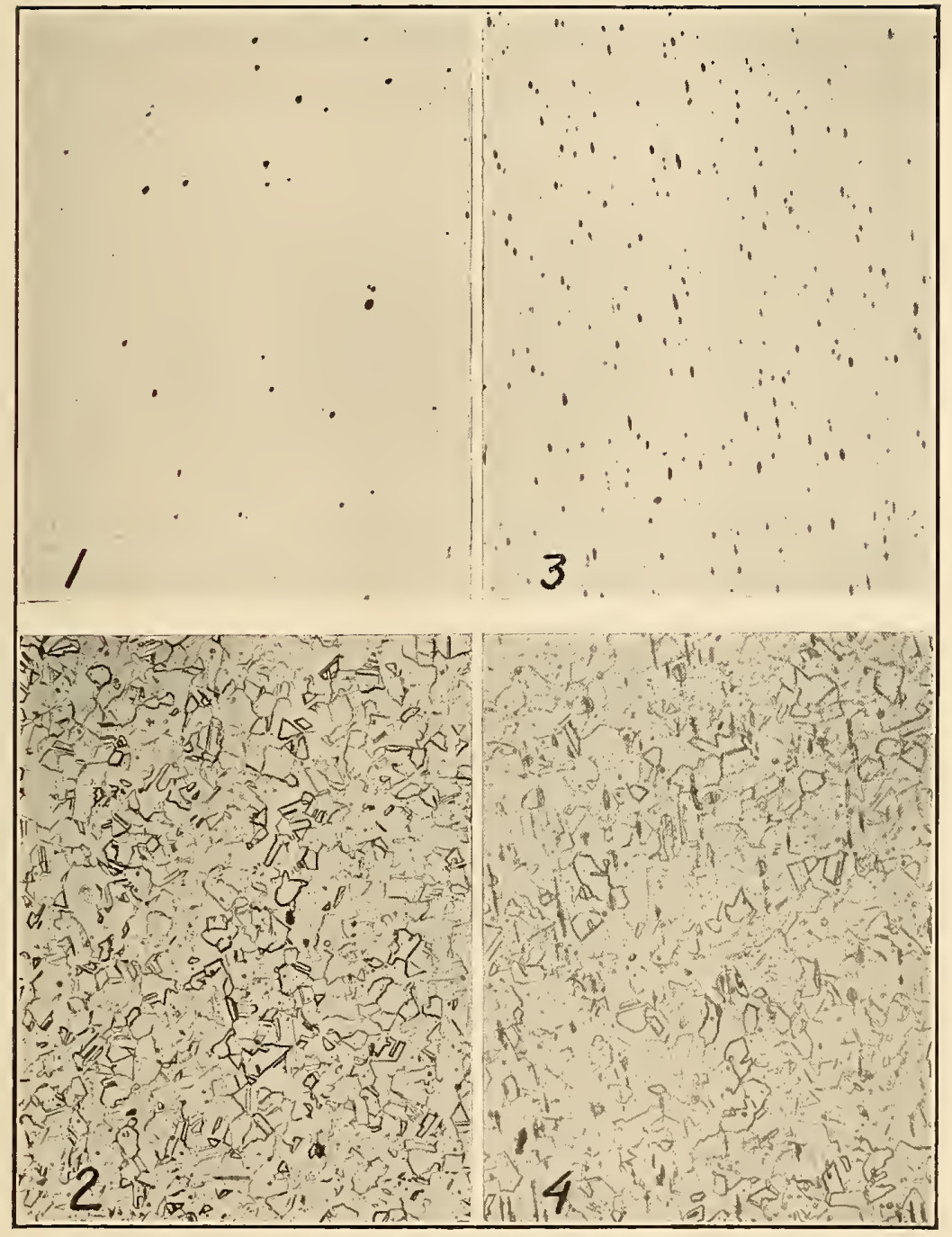

Fig. 8.- Monel metal. $\times 100$

1 and 3 , unetched; 2 and 4 , ctched with a solution of 30 parts acetic acid, 30 parts nitric acid, and

1 and 2 , Monel metal B. A rerage impact ralue 129,0 foot-pounds

3 and 4 , Moncl metal $A$. Arerage impact value 84.32 foot-pounds

There were more inclusions in Moncl metal A than in $B$. The majority of the inclusions

were probably of magnesium sulphide as was indicated by their solubility in water but not in alcohol. The grain size was about the same for both samples 


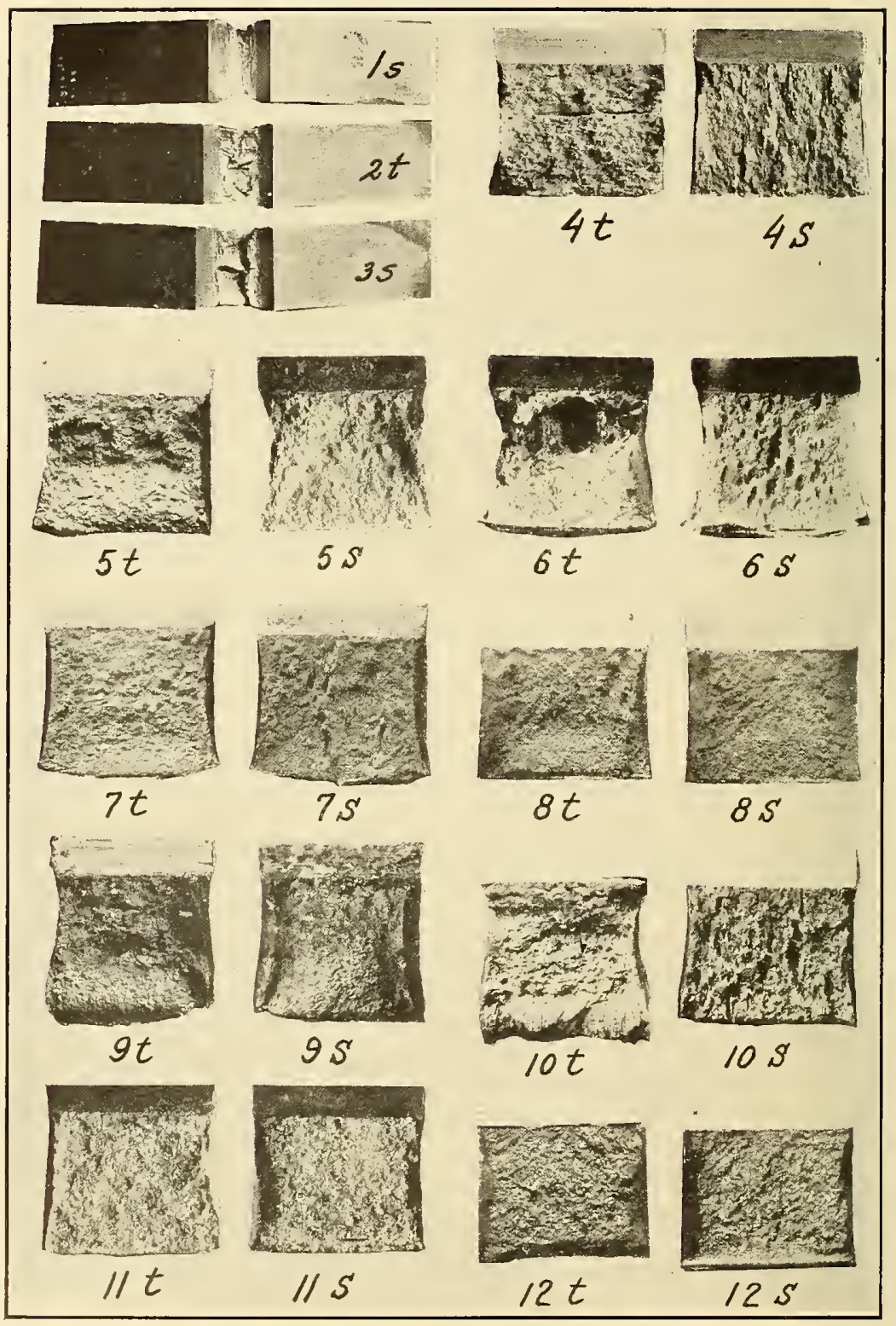

FIG. 9. - Fractures of impact specimens

" $t "=$ notch in the plane of rolling

" $s$ " =notch at right angle to the plane of rolling

1s. Monel metal $B$, impact value 129.2 foot-pound

2t. Monel metal A, impact value 93.35 foot-pounds

$3 s$. Monel metal A impact value 75.30 foot-pounds

Note the fissure in the fracture; indication of fibrousness

4. Duralumin B, fibrous; impact values; $t=13.30$ foot-pounds; $s=9.52$ foot-pounds

5. Brass $B$, slíghtly fibrous; $t=27.92$ foot-pounds; $s=24,60$ foot-pounds

6 . Aluminum bronze, fibrous; $t=83.80$ foot-pounds; $s=58.85$ foot-pounds

7 Phosphor bronze, fibrous; $t=30.65$ foot-pounds; $s=24.87$ foot-pounds

8. Nickel silver, not fibrous; $t=14.65$ foot-pounds; $s=12.97$ foot-pounds

9. Armeo iron, slightly fibrous; $t=54.62$ foot-pounds; $s=52.95$ foot-pound

10. Wrought iron, fibrous; $t=58.40$ foot-pounds; $s=39.37$ foot-pounds

11. Roiler plate, slightly fibrous; $t=16.33$ foot-pounds; $s=15.22$ foot-pounds

12, $31 / 2$ per cent nickel stcel B, slightly fibrous; $t=24.97$ foot-pounds; $s=25.27$ foot-pounds 
Technologic Papers of the Bureau of Standards, Vol. 19

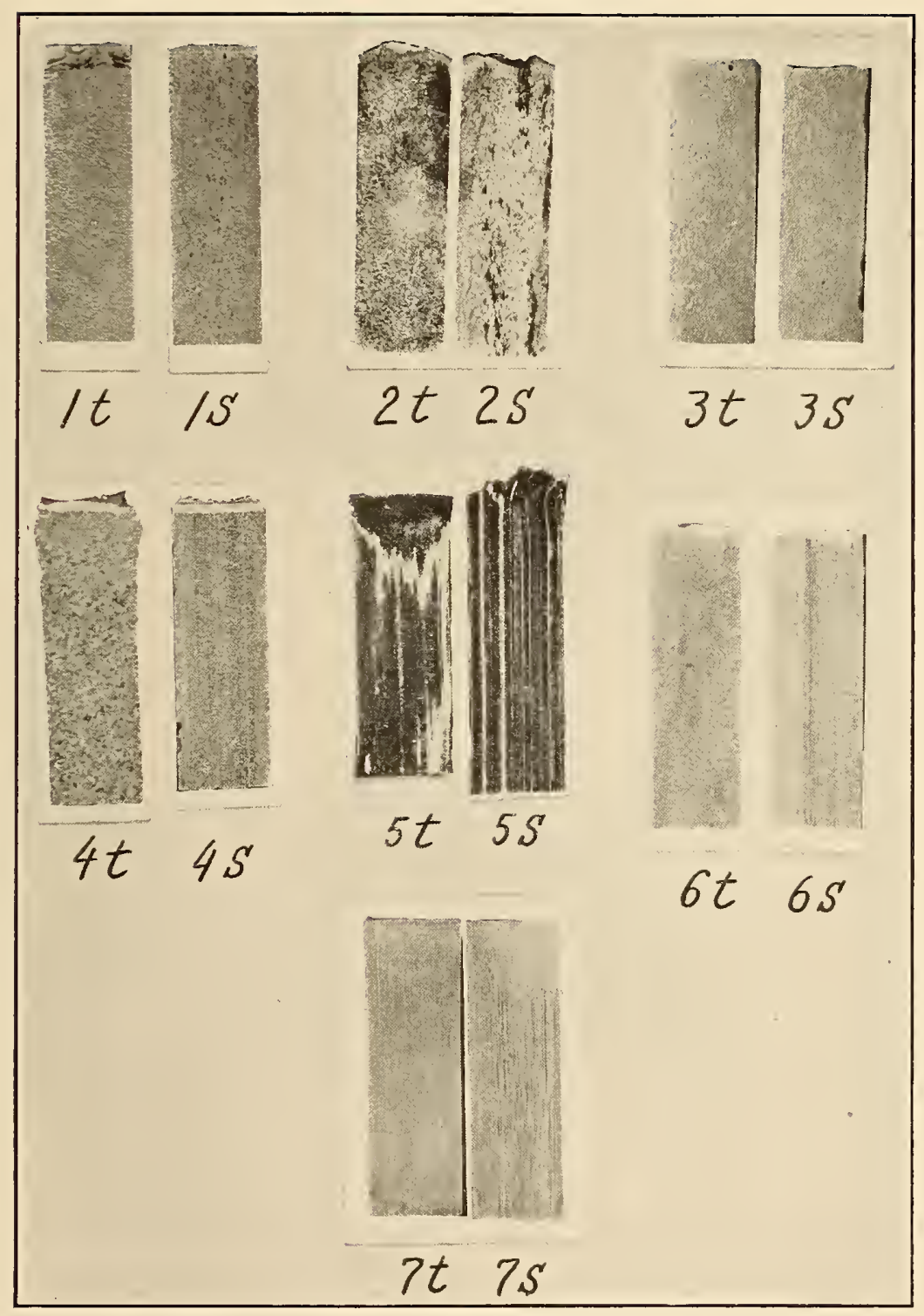

FIG. 10.-Macrostructure of some of the metals, showing "fiber." Natural sizc

" $t "=$ notch in the plane of rolling

" $s$ " = notch at right angle to the plane of rolling

1. Duralumin, etehed with 10 per cent sodium hydroxide solution

2. Phosphor bionze, etehed with ammonium hydroxide and hydrogen reroxide

3. Nickel silver, ctched with concentrated nitrie aciol

4. Armeo iron, etched with ammonium persulphate

5. Wrought iron, etched with hot 1:1 hydroehlorie acid in water

6. Boiler plate, etched with hot $1: 1$ hrdrochlorie acid in water

7. $3_{2}^{1}$ per eent niekel steel, etehed with hot 1:I hydroehlorie acid in water 
Technologic Papers of the Bureau of Standards, Vol. 19

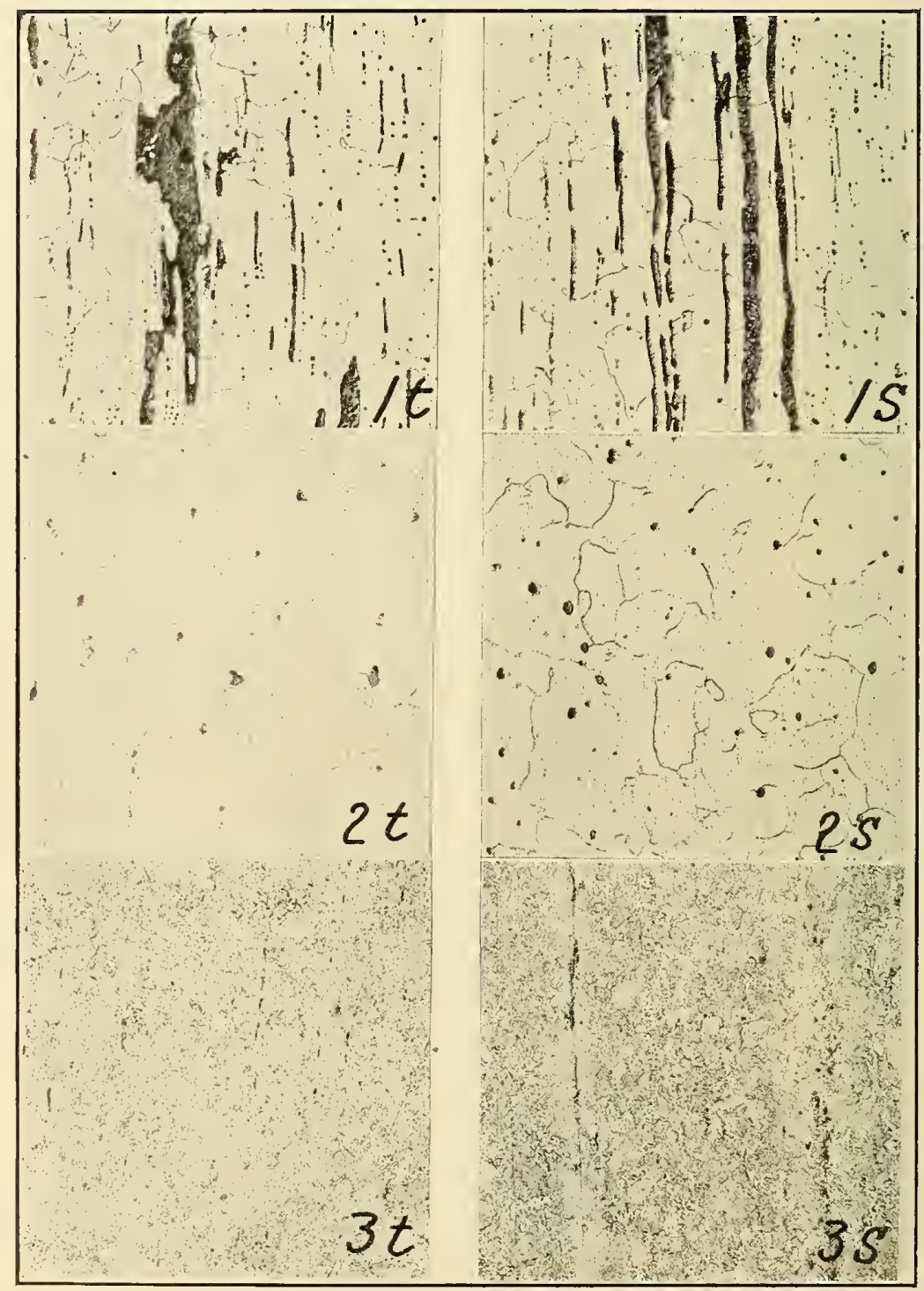

Fig. 11.-Ferrous metals. $\times 100$

Etched with 2 per cent nitric acid in alcohol " $t$ " =noteh in the plane of rolling

" $s "=$ notch at right angle to the plane of rolling

1. Wrought iron, fiber produced by the slag threads

2. Armeo iron

3. 32 per cent nickel stecl $B$ 
"fiber," the same effect may be produced by the characteristic structural constituents of a material, such as slag in the wrought iron and the hard particles of the copper aluminum compound in duralumin. In the cast state most of the inclusions are lodged in the interstices of the relatively large pine tree or dendritic crystals which develop upon solidification. During the rolling process the inclusions are rearranged into long streaks, and if soft enough at the rolling temperature they are flattened out into thin sheets or laminations. In the plane of rolling the inclusions are merely widened out and flattened. In the plane at right angle to the plane of rolling the groups of inclusions appear as long threads.

The fibrous structure of the metals is undoubtedly associated with the directional differences in impact properties. Figure 9 shows that the materials which gave the largest variation in the notchedbar values for the specimens having notches in the plane of rolling, and those which had notches at right angle to the plane of rolling show the most pronounced fibrous structure.

\section{MICROSTRUCTURE}

The microscopic examination showed inclusions in considerable amounts, both in the ferrous and nonferrous metals.

\section{(a) FERROUS METALS}

In wrought iron this is, of course, more pronounced than in any of the other materials. As can be seen in Figure 11, 1, the slag inclusions in the top section are more irregularly shaped, whereas in the side section they appear longer, thinner, and, in general, more uniform. The Armco iron and the $31 / 2$ per cent nickel steel were only slightly fibrous.

\section{(b) NONFERROUS METALS}

Among the nonferrous metals the greatest amount of inclusions was found in duralumin, aluminum bronze, and phosphor bronze.

(1) Duralomin (fig. 12,1).- In the section parallel to the plane of rolling hard copper aluminum particles are arranged in a dendritic pattern. It will be noted that in this section the grains are equiaxed, whereas in the side section the grains have an elongated form.

(2) Aluminum Bronze (fig. 13). - In the top section the segregates of inclusions are in the form of wide bands; in the side section they show as thin streaks. The individual inclusions themselves were very small and hard, and apparently their shape had not been changed to any appreciable extent by the rolling.

(3) Phosphor Bronze (fig. 14).-The fiber here was caused by the usual type of segregates of small inclusions and also by loug intercrystalline threads or films apparently filled in by some readily soluble product. Such films are not infrequently found in phosphor bronze with which difficulty is encountered in rolling.

$34208^{\circ}-25-3$ 
(4) Nicker Silver.-Figure 12, 2, shows what may be considered as a transition stage in the production of fiber. The nickel silver apparently was not reduced very much in rolling and the dendritic structure is still in evidence. It can be seen, however, that in the side section the dendrites are more elongated than in the top section. In this materisl the dendritic pattern was not produced by the presence of a separate constituent or by an excessive number of inclusions, but by the variation in concentration of the same solid solution. In Figure 12,3, the same material etched in a different manner shows a uniform one-phase structure. This material did not show any marked difference in notched-bar values to be attributed to "fiber."

(5) BRAss.-Another cause which may contribute to the fibrous condition of a metal is the variation in composition due to segregation, which may be sufficiently great to cause the formation of another phase, although the alloy according to its average chemical composition would ordinarily consist of only one phase. This was noted in the case of the brass. Figure 15, 1 , shows a layer in a side section of a brass specimen, in which some $\beta$ brass may be detected. The greater part of the material, of course, is $\alpha$ brass, which is softer than the $\beta$ brass. The streak of the latter constituent, together with the large number of inclusions surrounding it, have introduced the element of fiber. It will be noted that the precipitation of the $\beta$ brass in this spot and the presence of the large number of inclusions have materially diminished the grain size. Figure 15, 2, shows that the surrounding structure is much larger grained.

\section{DISCUSSION OF RESULTS}

\section{GENERAL RELATION BETWEEN THE IMPACT AND THE SLOW- BEND VALUES}

In Figure 7 the metals are arranged in the order of the magnitude of their impact values, and these are compared with the slow-bend values and with the values for other properties of the materials.

It will be noticed that in most cases the slow-bend values are lower than the impact values, equal or lower impact values occurring in the case of steel only. For all the other materials the slow bend and the impact curves follow each other (see fig. 16), except for Monel metal B.

It will be noted that Monel metal $\mathrm{B}$ showed considerably higher resistance to impact than the Monel metal A.

All other properties of these two materials, including the slow-bend values, were practically the same (the slow-bend values for Monel metal B were even lower than those for Monel metal A). The micrographic examination of the two materials showed that the Monel metal A contained a much larger number of inclusions than the Monel metal B. Apparently, there is no well-defined relation 
Technologic Papers of the Bureau of Standards, Vol. 19

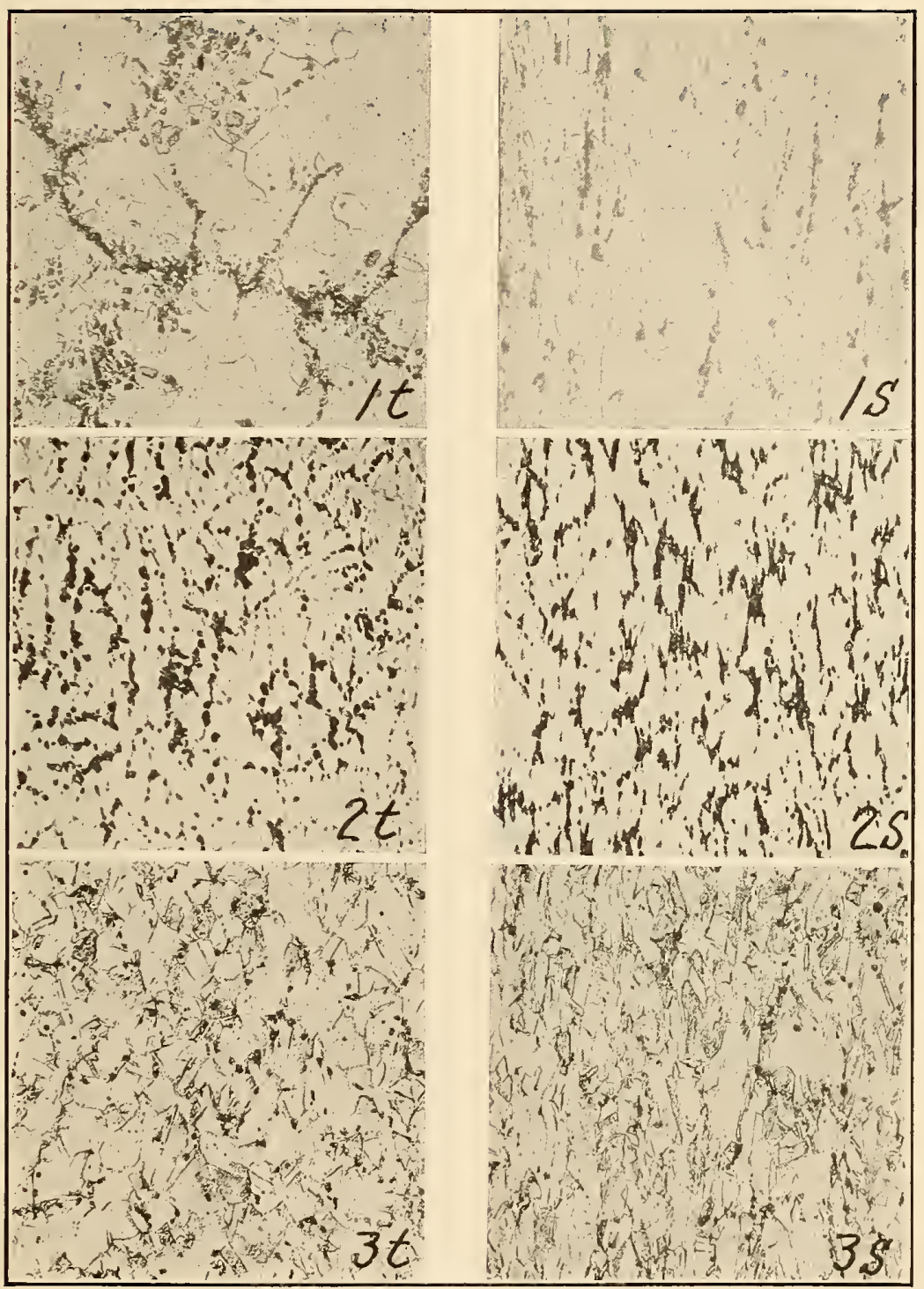

FIG. 12.-Duralumin and nickel silver

$" t "=$ notch in the plane of rolling

" $s "=$ notch at right angle to the planc of rolling

1. Duralumin $B \times 100$. Etched with 10 per cent lydrovide solution

In the top section the dendritic casting pattern of the hard copper aluminum particles is still in evidence and the grains are equiaxed; in the side scction the particles are arrnyerl into streaks and the grains are elongated

2. Nickel silver $B, \times 50$. Etched with ammonium hydroxide and hydrogen peroxile

3. Nickel silver B. $\times 100$. Etched with a solution of 30 parts acetic acid, 30 parts nitric acid, 40 parts water

In the side section the dendrites and the grains are elongated, while in the top section the

original structure of the east state is more nearly preserved 
Technologic Papers of the Bureau of Standards, Vol. 19

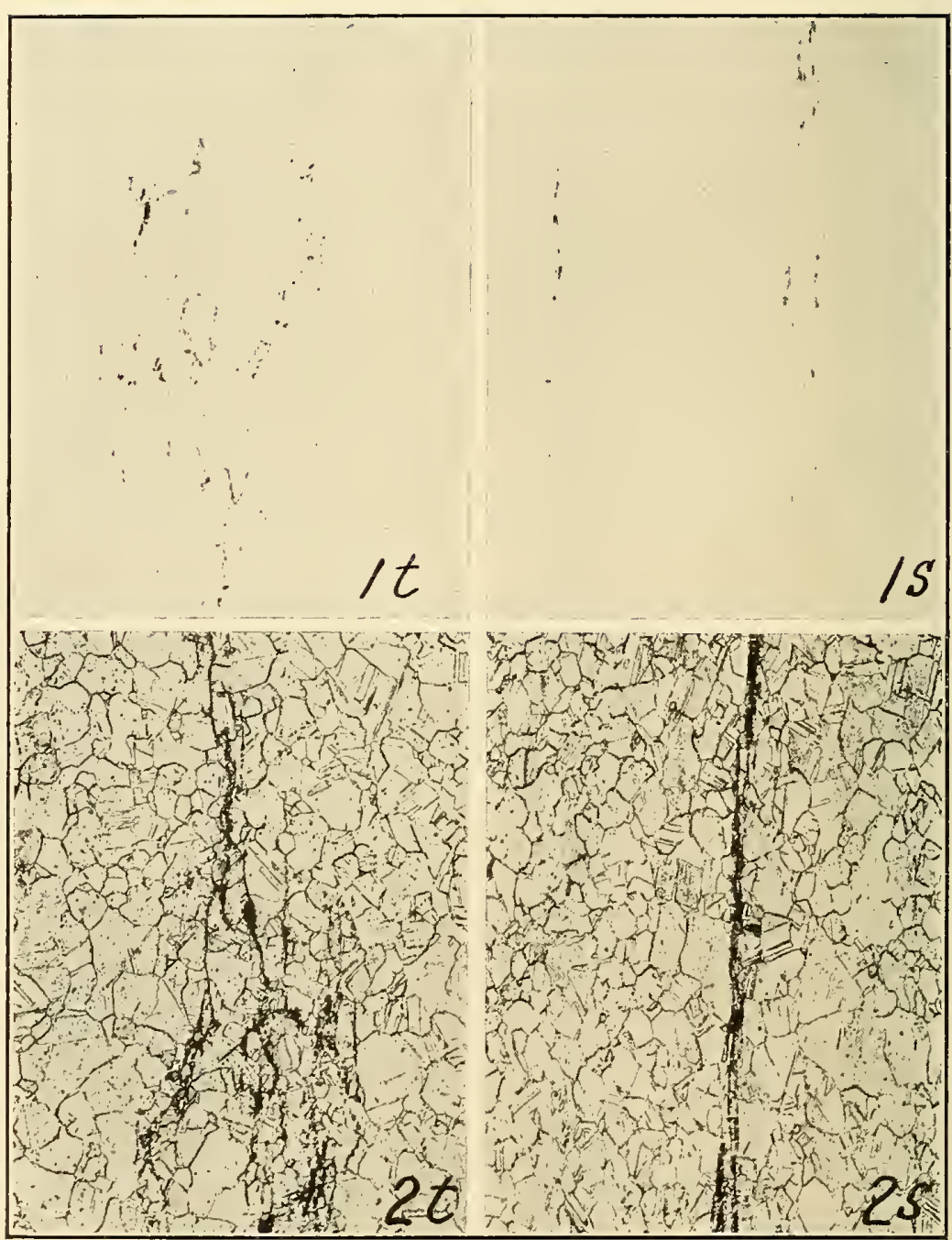

FIG. 13.-Aluminum bronze. $\times 100$

" $t$ " =notch in the plane of rolling

"s" =notch at right angle to the plane of rolling

s = notch at rig

2. Same spots etched with ammonium hydroxide and hydrogen peroxide

In the top section the segregates of inclusions appear as wide streaks; in the side section as narrow threads. The individual inclusions were very small and hard and were apparently not changed by rolling 
Technologic Papers of the Bureau of Standards, Vol. 19

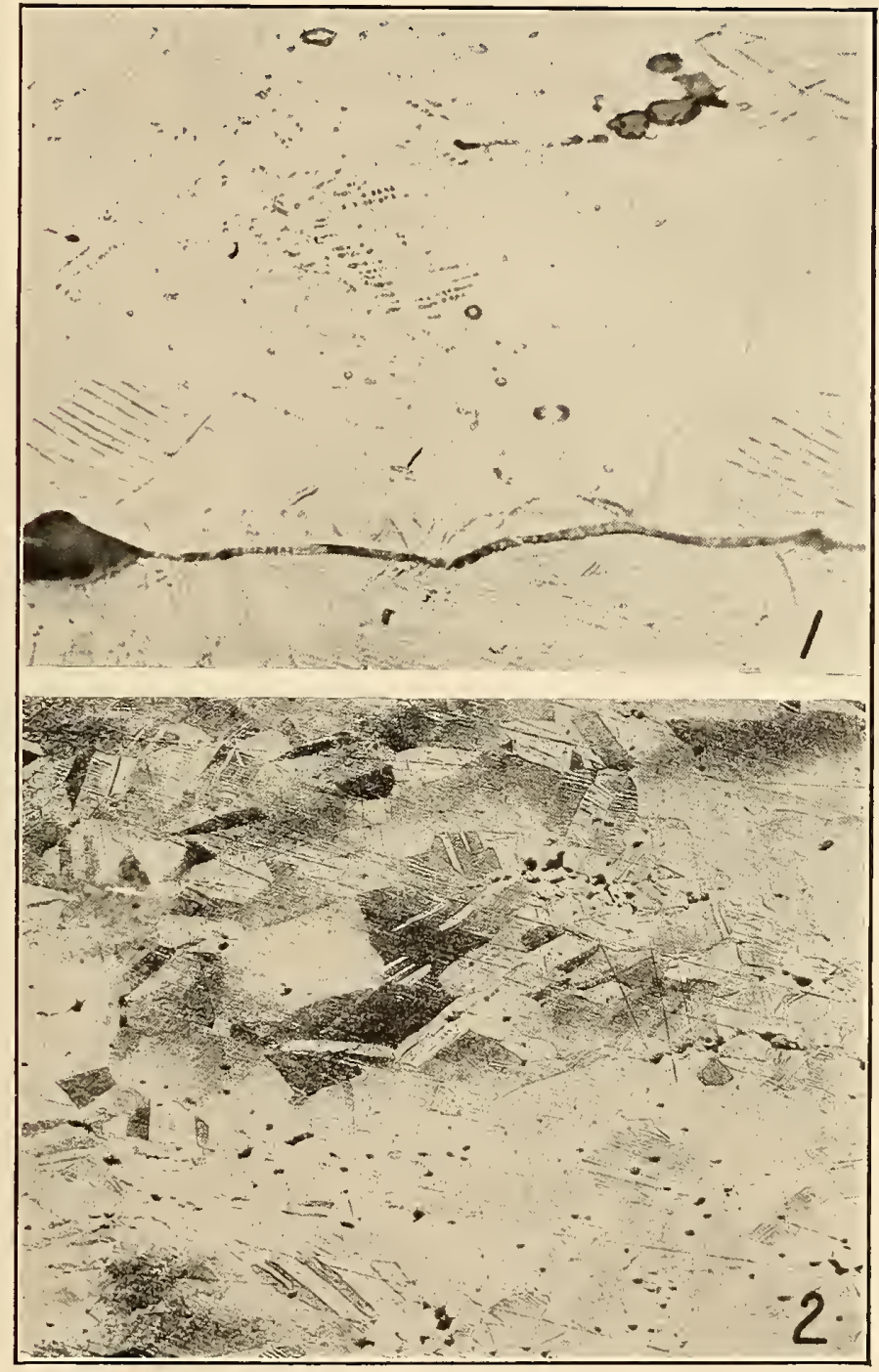

FIG. 14.-Phosphor bronze

Side sections ctehed with ammenium hydroxide and hydrogen peroxide

1. Shows two types of inelusions; small insoluble blue inclusions and long intererystalline threads filled with a brownish readily soluble substance. $\times 500$

2. Shows "ghostlike" appearanee of contaminated area. Tlie dirty portions etch lighter and simulate the "ghost" lines in steel. $\times 100$ 


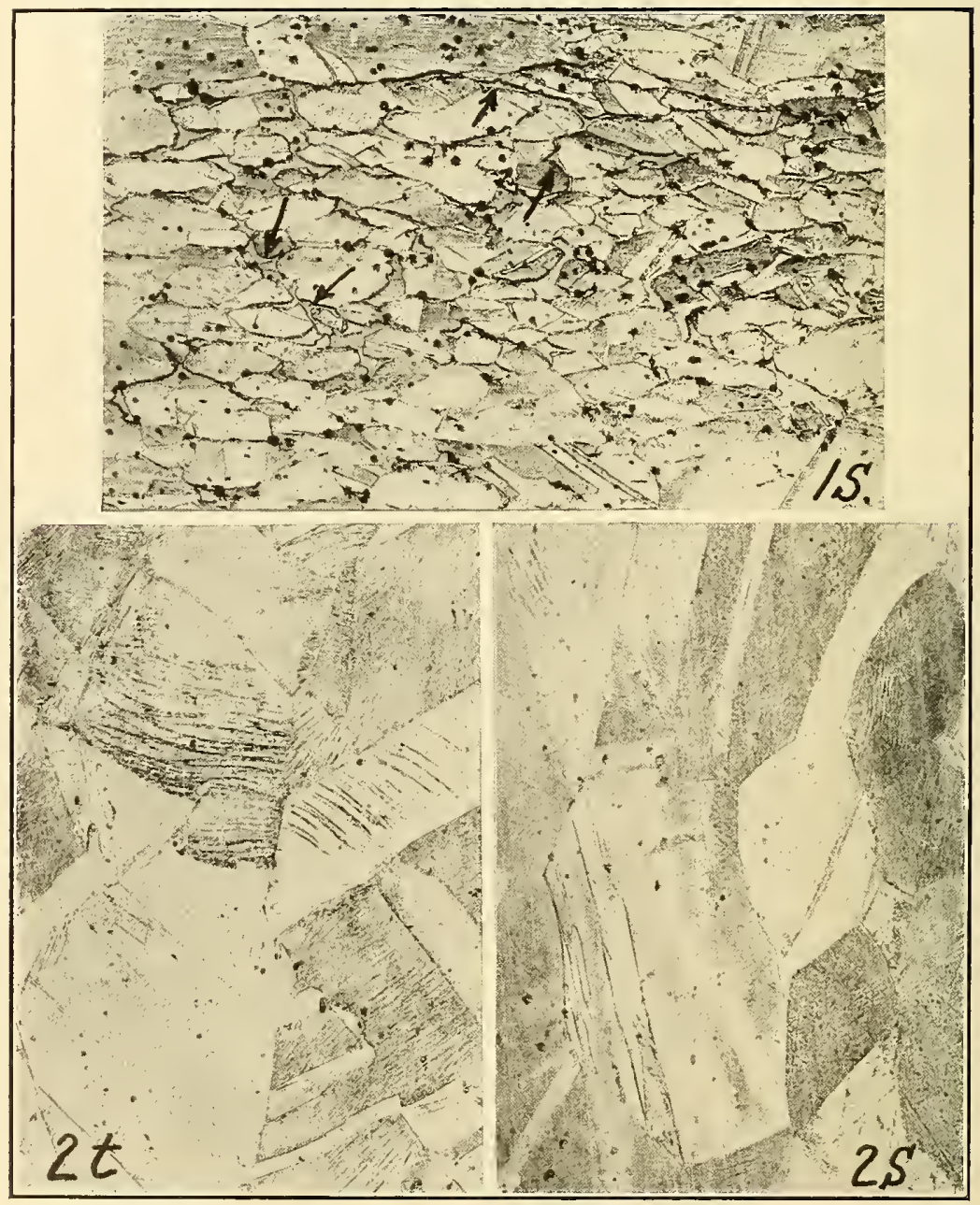

FIG. 15.-Brass. $\times 100$

Etched with ammonium hydroxide and hydrogen peroxide " $t "=$ notch in the plane of rolling

" $s "=$ notch at right angle to the plane of rolling

1. Shows separation of $\beta$ phase in a segregated streak in a hrass. The $\beta$ constituent is indicated by the arrows. The inclusions are very numerous in this streak and the grain size is smaller

2. Shows the structure of the material outside the streak 
between the notched-bar values, whether obtained in an impact or in a slow-bend test, and the tensile properties of these materials. Some values, however, which may be obtained in a slow-bend test are pretty definitely related to the values obtained in the tensile tests (see fig. 17). Thus, the maximum bending moment is approximately proportional to the tensile strength and the bending moment corresponding to the "proportional limit" of a slow-bend diagram is approximately proportional to the tensile yield point.

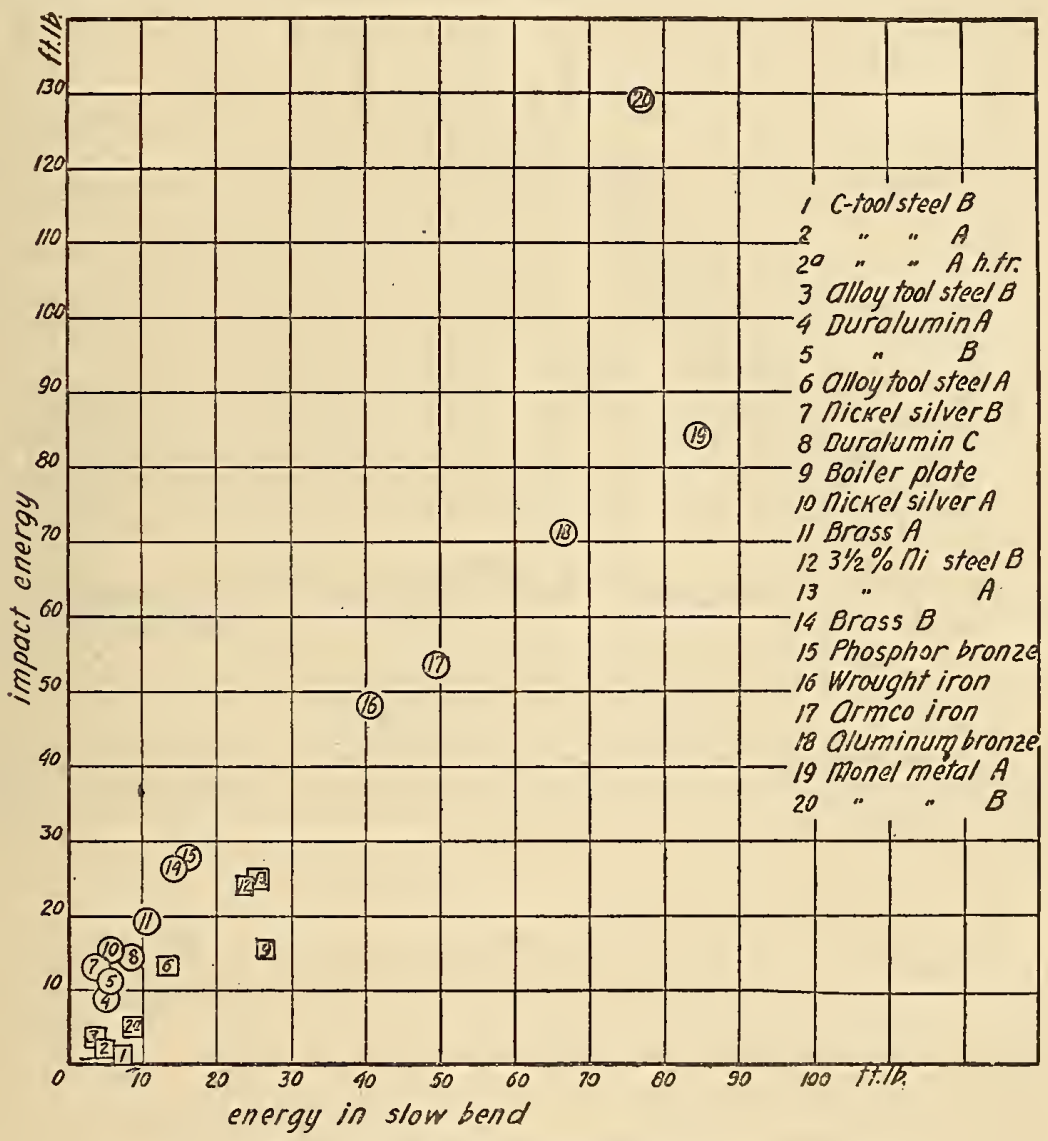

Fig. 16.-Relation between the slow-bend and the impact values

\section{VARIATION ALONG THE LENGTH OF A BAR OF THE IMPACT AND OF THE SLOW-BEND VALUES}

The materials used in this investigation were fairly uniform in their properties. In the case, however, of the alloy tool steel notched bar values varied quite considerably. This was shown (see fig. 1S) by both impact and slow-bend tests, the impact method being somewhat more sensitive. In these and other tests on more uniform materials the average percentage deviation of individual values from the average value for a given material is about the same for 


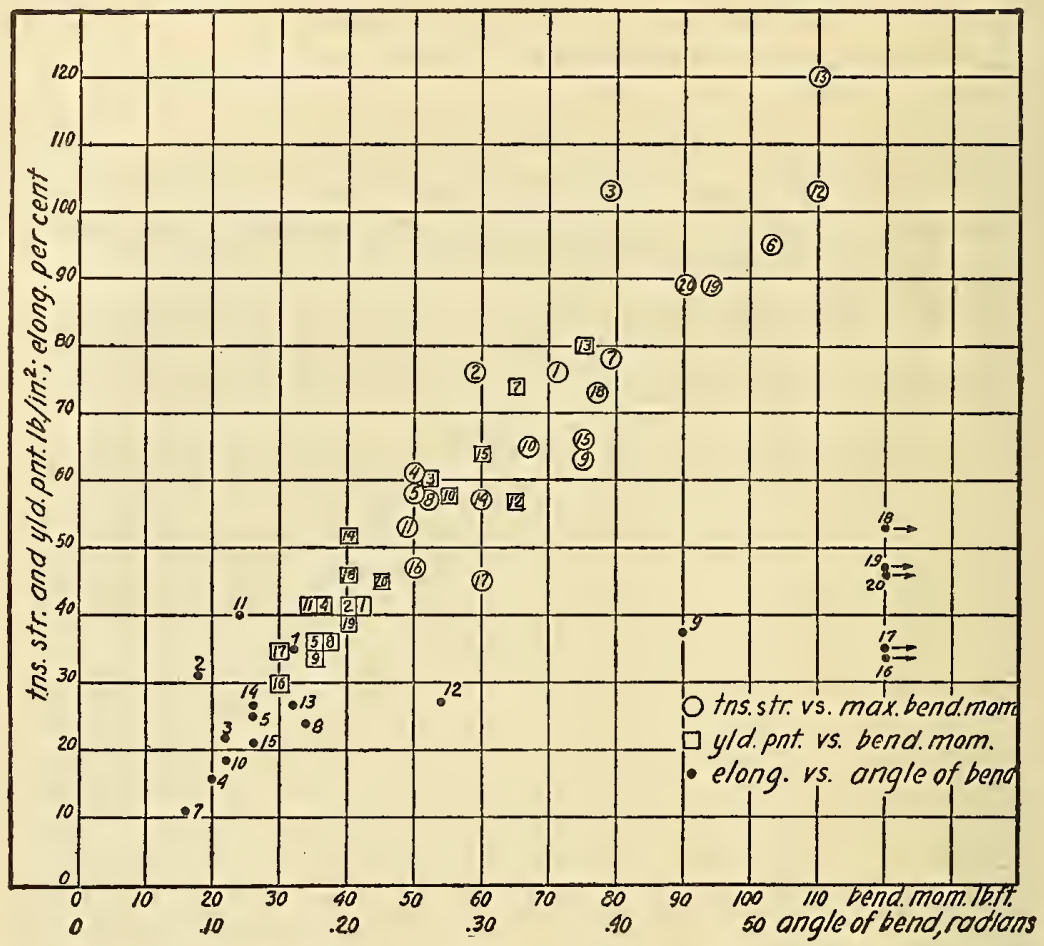

FIG. 17.-Relation between some of the slow-bend values and the values for the tensile properties of the materials

The numbers indicate the materials as given in Figure 7. The yield point is plotted against the bending moment corresponding to the portion of the diagram near $B$. (See fig. 4.) The angle of bend is that at which the bending moment begins to decrease rapidly or at which the resistance of a specimen drops suddenly to zero.

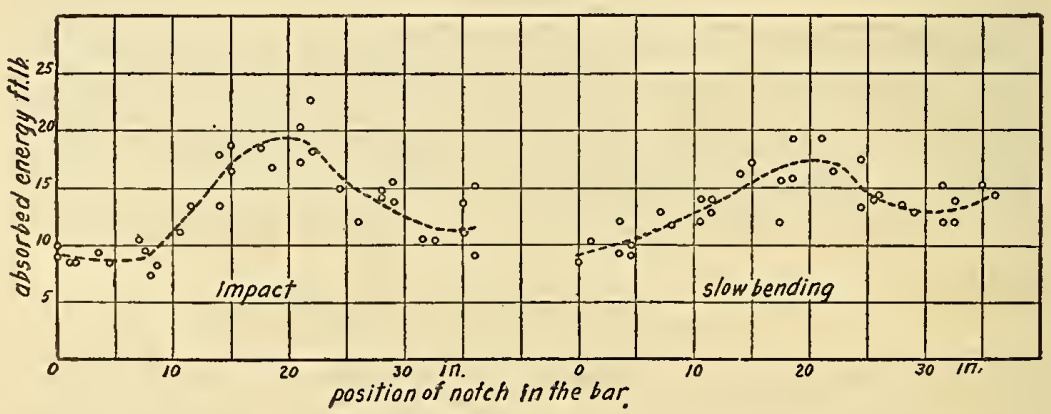

FIG. 18.-Variation of the impact and of the slow-bend values along the length of a bar of alloy tool steel $A$

This steel showed considerable variation of the notched bar properties, the other materials being more nearly uniform. 
impact and for slow bend. A smaller variation should not necessarily be considered an indication of greater accuracy of a given method of testing. Though this might be the case, it is, however,

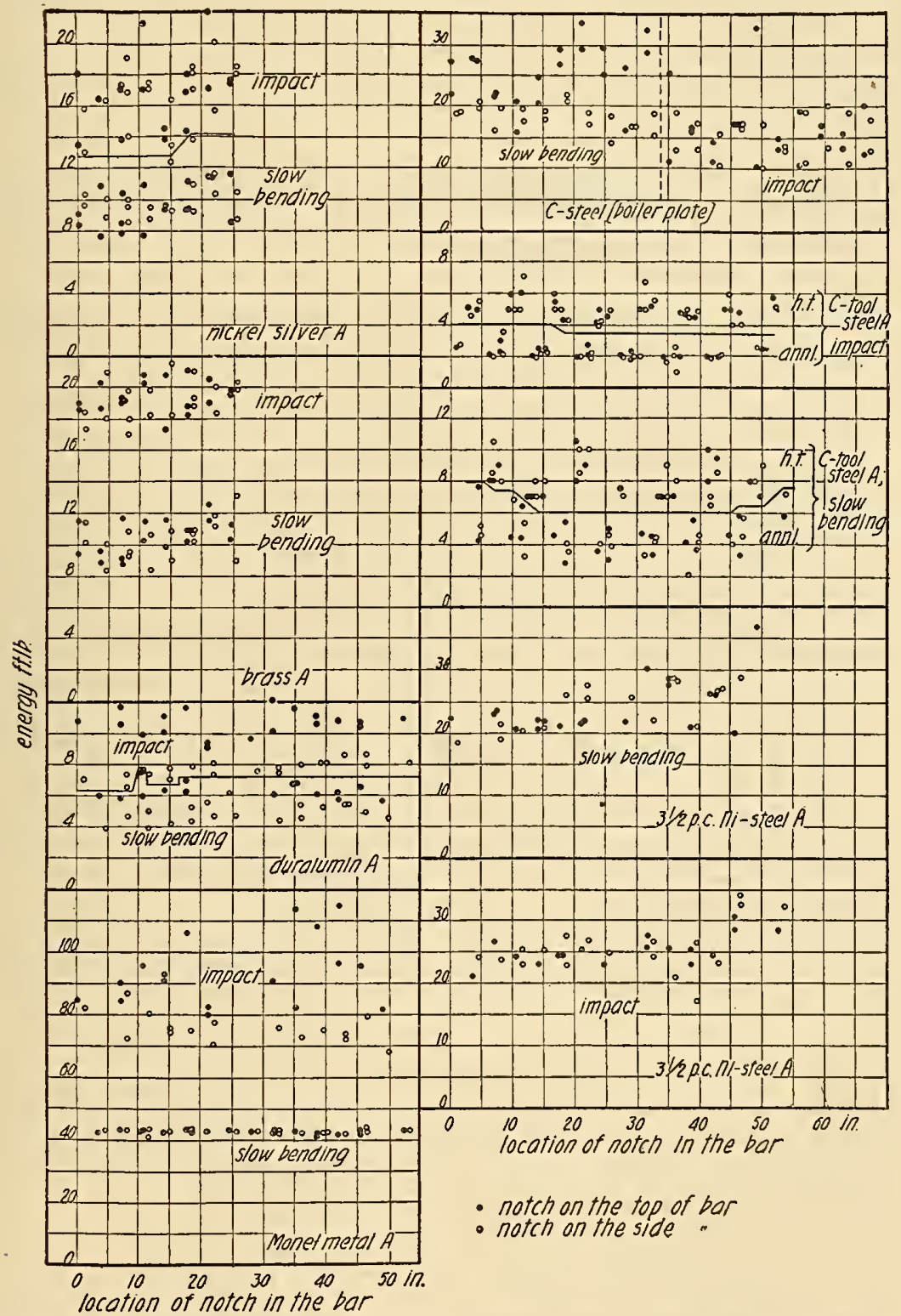

FIG. 19.-Variation of the impact and of the slow-bend values along a bar in series 1 tests (slow-bend values for Monel metal are not reduced to the same angle of bend as in impact machine)

equally true that the uniformity of results may indicate that a given method does not show small differences in the resistance of the specimens. Thus, for Monel metal A (see fig. 19) the variation of 
the individual results for the impact test is much greater than for the slow-bend test, but it is evident that this variation does not indicate the inaccuracy of the impact method because the latter was sufficiently accurate to show a decided difference between the specimens having notches differently placed in the bar. For this reason no use was made of the values of deviation of the individual results from the average.

3. DIFFERENCE IN THE IMPACT AND THE SLOW-BEND VALUES BETWEEN THE SPECIMENS HAVING NOTCHES IN THE PLANE OF ROLLING AND THOSE WITH THE NOTCHES AT RIGHT ANGLE TO THE PLANE OF ROLLING

This difference is shown graphically in Figure 20. In a specimen having the notch in the plane of rolling (value $A_{t}$ ) the fracture

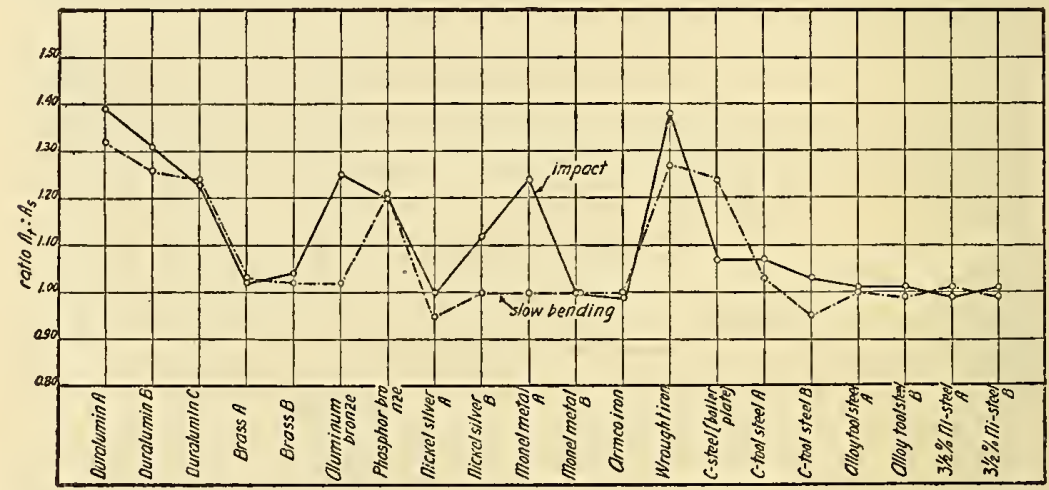

Fig. 20.-Ratios of average values of energy for the "standard," "sharp," "round," and "deep" notches for the specimens with the notch on the top of the bar and with the notch on its side.

In a specimen with the notch on the top (value $A_{t}$ ), the fracture developed at the right angle to the direction of rolling and to the plane of rolling. In a specimen with the notch on the side (value $A_{8}$ ) the fracture developed at the right angle to the direction of rolling but in a direction parallel to the plane of rolling.

developed at right angle to the direction of rolling and to the plane of rolling. In a specimen with the notch normal to the plane of rolling (value $A_{s}$ ) the fracture developed at right angle to the direction of rolling, but parallel to the plane of rolling. The average ratios $A_{t} / A_{s}$ for all tested materials are given in Table 4 .

TABLE 4.-Average ratios $A_{\mathrm{t}} / A_{\mathrm{B}}$ for all tested materials

\begin{tabular}{|c|c|c|c|c|}
\hline \multirow{2}{*}{ Machine } & \multicolumn{4}{|c|}{ Notch } \\
\hline & "Sharp" & "Standard" & "Round" & “Deep" \\
\hline $\begin{array}{l}\text { Impact. } \\
\text { Slow bend. }\end{array}$ & $\begin{array}{l}1.20 \\
1.15\end{array}$ & $\begin{array}{l}\text { 1. } 16 \\
1.08\end{array}$ & $\begin{array}{l}1.08 \\
1.04\end{array}$ & $\begin{array}{l}\text { 1. } 05 \\
1.05\end{array}$ \\
\hline
\end{tabular}


The values given in Table 4 show that the impact method is morc responsive than the slow-bend method to the variation in the position of the notch in relation to the rolled surface. Incidentally, this table indicates also that the "sharp" notch is the most sensitive of those used. The metallographic cxamination (see "Metallographic examination") has shown that a large difference in the notched-bar values for the specimens with the notch on the top (in the plane of rolling) and those with the notch on the side (at right angle to the

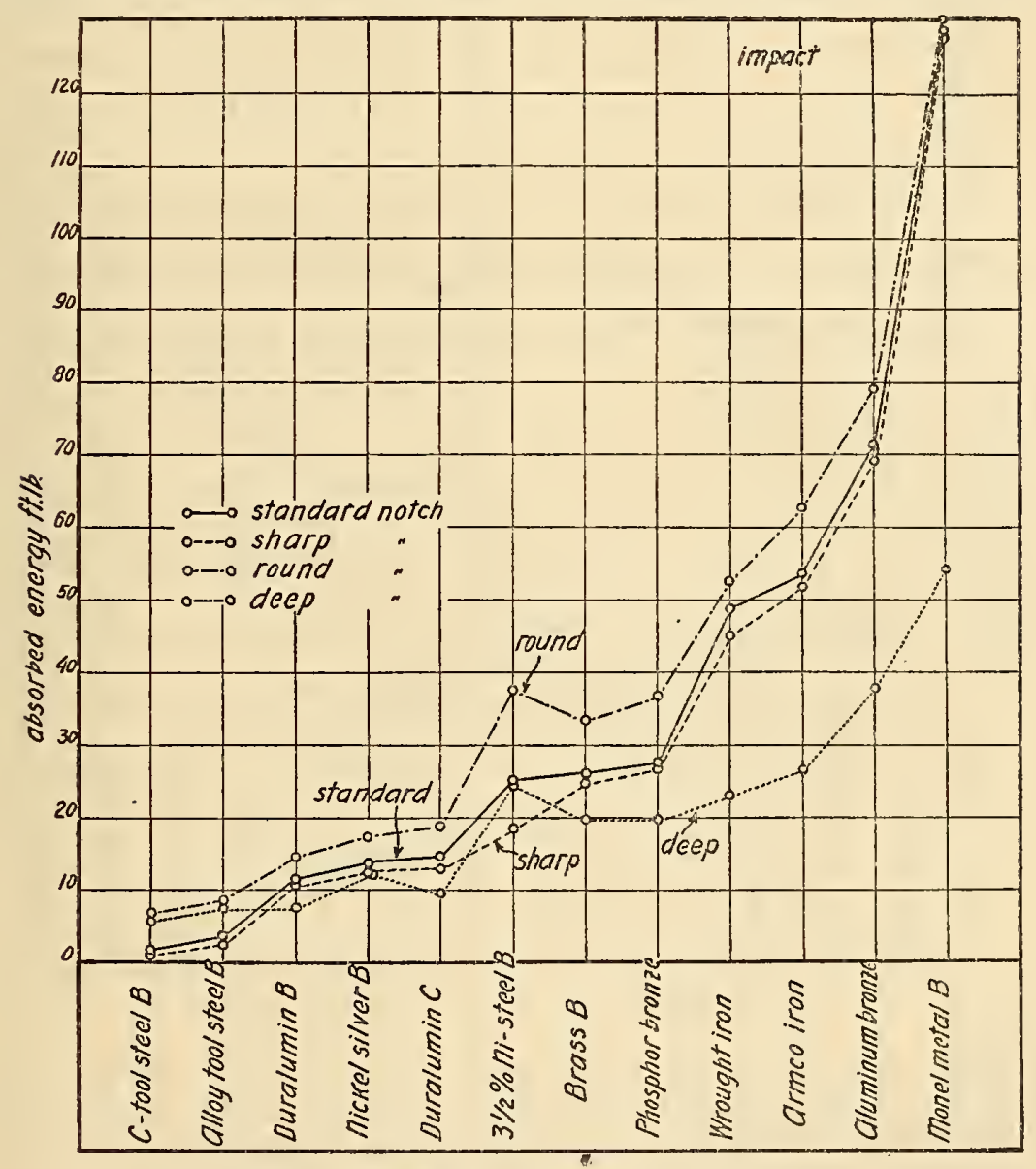

FIG. 21.-Effect of notch on the impact values

plane of rolling) is associatcd with fibrous or lamellar structure of a material. In a specimen of homogeneous material the fracture extends across the specimcn, and once started it acts itself as an notch. It may happen, however, that before the fracture has penetrated into inclusion a shear failure occurred in the planc of the inclusion, learing the unbroken portion of the specimen unnotched. A greater resistance, therefore, may be expected for a specimen with the notch parallel to the plane of inclusion than with the notch at right angle to it. 
4. RELATIVE EFFICIENCY OF THE DIFFERENT NOTCHES IN DETECTING DIFFERENCES IN THE NOTCHED-BAR RESISTANCE OF THE MATERIALS

In Figure 21 are shown the impact and in Figure 22 the slow-bend values for each of the four notches used in series 2 . The effect of the notch is very similar for both methods. Of the four notches used in this investigation the "standard," "sharp," and "round" notches, although giving different, numerical values, are about equally

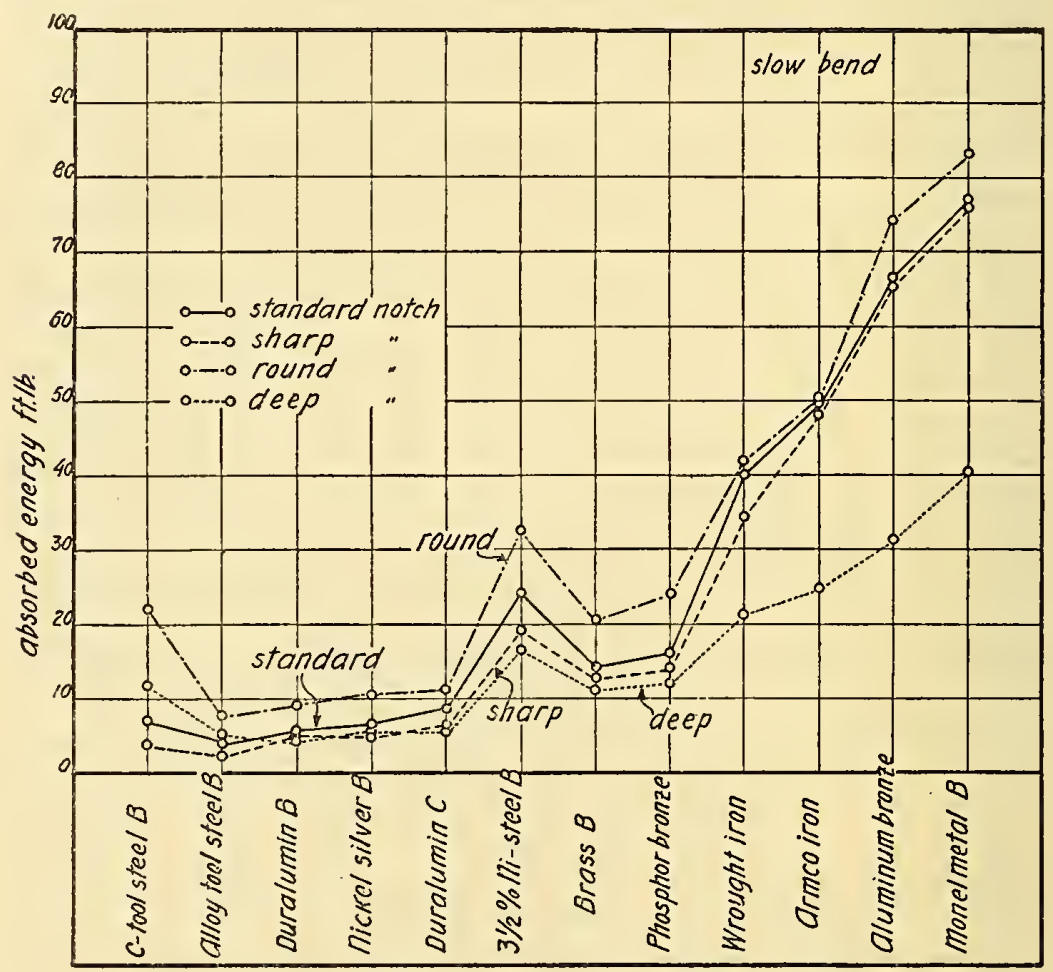

FIG. 22.-Effect of notch on the slow-bend values

efficient. The fourth, the "deep" notch, is apparently less efficient than the others, showing less difference in the notched-bar properties of materials. For brittle materials it gives larger values than the "standard" and "sharp" notches and for tough materials smaller values.

\section{EFFECT OF VARYING THE RADIUS OF THE NOTCH ON THE ENERGY}

In this series of tests the net thickness of specimen was in all cases $8 \mathrm{~mm}(0.315 \mathrm{inch})$ and the radius of notch was $0 ; 0.25 \mathrm{~mm}$ (0.01 inch) and $1 \mathrm{~mm}$ (0.0394 inch). 
The effect of the radius of the notch is shown in Figure 23. For both the impact and the slow-bend methods the absorbed energy
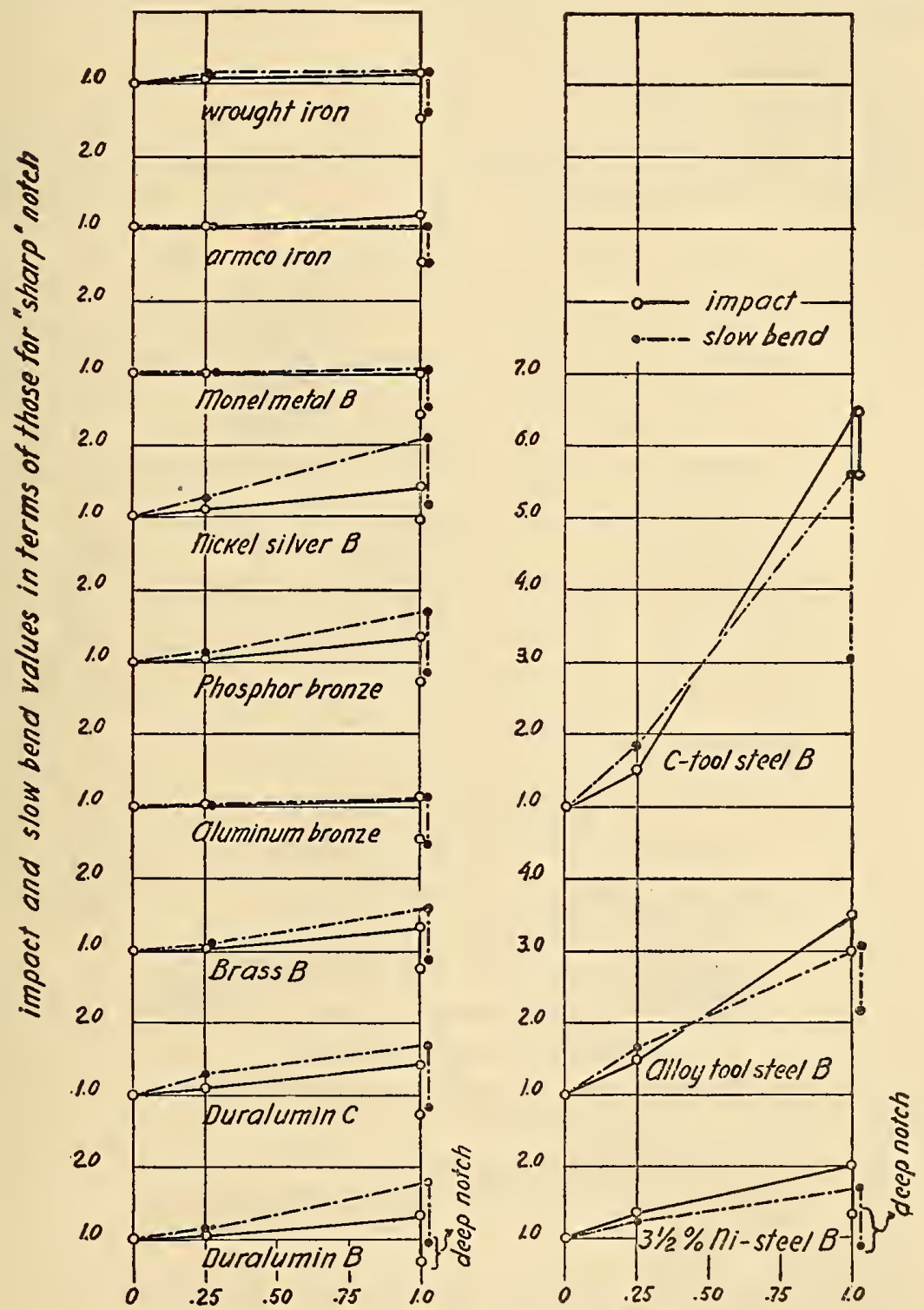

radius of notch $\mathrm{mm}$

FIG. 23.-Effect of the radius of notch on the impact and on the slow-bend values

All values are given in terms of those for the "sharp" notch. The vali.es for "deep" notch should not be compared directly with the other values, as the "deep" notch differed from them in depth.

has an approximately linear relation to the radius of notch, and, on the whole, both methods seem to be about equally responsire to changes in the radius of the notch. 
It will be noted that the rate of increase of energy with the increase of the radius of notch is much greater for brittle materials like tool steels than for tough materials like Monel metal or aluminum bronze.

\section{EFFECT OF THE DEPTH OF THE NOTCH ON THE ENERGY}

The comparison was made for two notches-a "round" notch and a "deep" notch having the radius $1 \mathrm{~mm}$ and the depths 2 and $5 \mathrm{~mm}$, respectively. The curves which show the effect of the depth of

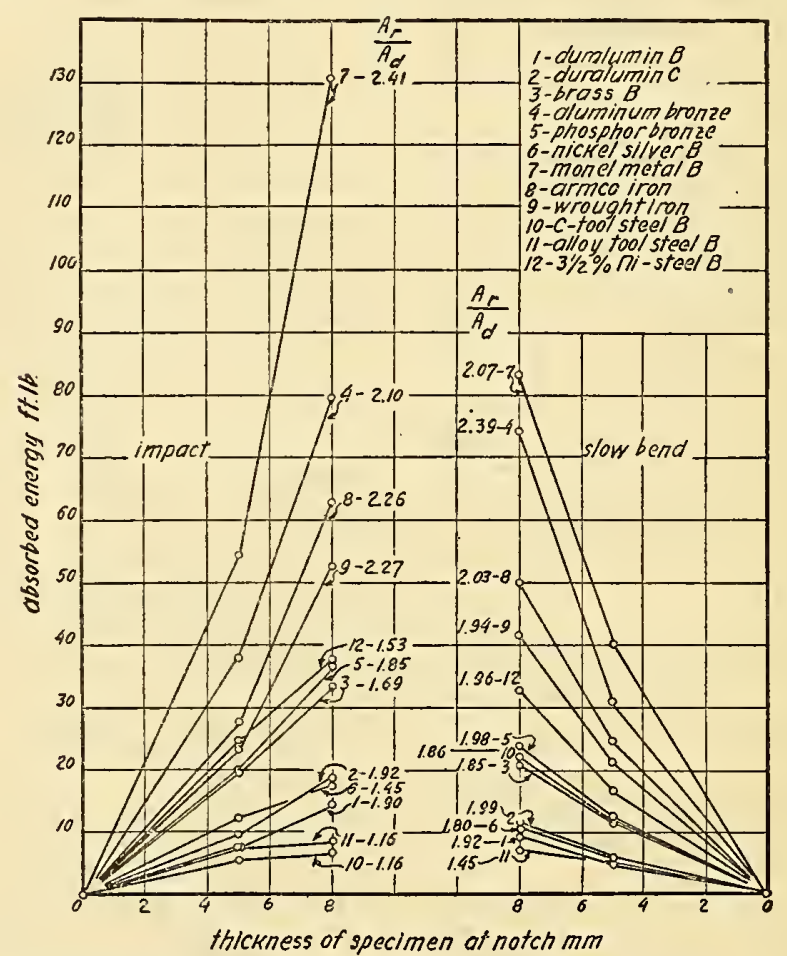

FIG. 24.-Effect of the depth of notch on the impact and on the slow-bend values

The radius of the notch was in all cases $1 \mathrm{~mm}(0.0394$ inch). The figures at the ends of the curves indicate the materials, and the values opposite these figures are the ratios of the energies for the "round" and "deep" notches.

notch (fig. 24) all pass through zero, because the resistance of a specimen with zero net thickness is equal to zero.

The figure at the end of each curve indicates the material, and the value opposite that figure is the ratio of absorbed energies for round and deep notches. It will be noted that the ratio decreases with the decrease of absorbed energy for both methods; that is, the effect of the depth of notch is greater for tough materials and is quite small for brittle materials. 
The results shown in Figure 25 seem to be scattered, and no attempt has been made to draw a curve. However, it will be noticed that the above ratio never exceeded 2.5 and seems to approach this value for tough materials. On the other hand, for brittle materials it is approaching unity. In all probability the curve of averages, if such could be drawn, would start at the ordinate 1.0 and would asymptotically approach the ordinate 2.5. The following interpretation may be given to Figure 25:

(a) For brittle materials the absorbed energy is nearly independent of the depth of notch (ratio of $A_{\mathrm{r}} / A_{\mathrm{d}}$ approaches 1.0).

(b) For tough materials it is approximately proportional to the square of the net thickness of specimen (the ratio of net thicknesses for the "round" and "deep" notches is 1.6 and the square of 1.6 is 2.56). This is discussed at a greater length in the Section XII.

\section{EMPIRICAL FOR- MULA FOR ABSORBED ENERGY}

On the basis of the experimetal data stated in the preceding paragraphs, itmay be assumed that if the energy can be expressed as a function of the geometrical characteristics of the speci-

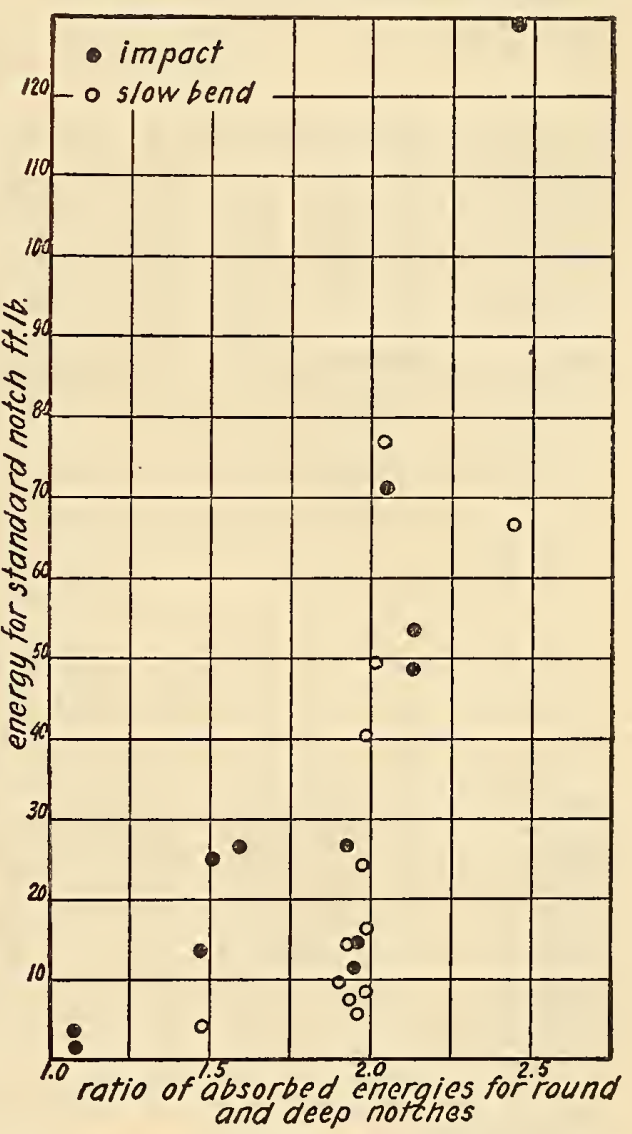

FIG. 25.-Increase of the effect of the depth of notch with the increase of absorbed energy men it should consist of at least two terms, one of which contains as a multiplication factor the first power of the radius of notch $(r)$ and the other the square of the net thickness of the specimen $(h)$.

Evidently both terms should disappear when $h=0$. The simplest form of a function, which satisfies these partially empirical and partially theoretical requirements, is this:

$$
A=\alpha b r h^{x}+\beta b h^{2}
$$


where $\alpha$ and $\beta$ are numerical coefficients, constant for a given material and $b$ is the width of the specimen, it being assumed that the energy is proportional to the width of the specimen.

As all values obtained from tests of materials are only approximations, the direct determination of $x$ is impracticable. By several trials it was found that the value $x=1 / 2$ fits the formula with a sufficient degree of accuracy. We have then

$$
A=\alpha b r \sqrt{h}+\beta b h^{2}
$$

In order to determine $\alpha$ and $\beta$, it is necessary to know the energy for two different notches. In this work $\alpha$ and $\beta$ were determined, using values for "sharp" and "deep" notches. In Tables 5 and 6 are found these values of $\alpha$ and $\beta$ and the calculated value of $A$ for "standard" and for "round" notches.

TABLE 5.-Coefficients $\alpha$ and $\beta$ determined from values for sharp and deep notches obtained in impact tests and calculated $A_{\mathrm{st}}$ and $A_{\mathrm{r}}$ as compared with experimental impact values

[All values are averages of those obtained with notches in the plane of rolling and at right angle to it]

[ $A=A_{1}+A_{2}=\alpha b \tau \sqrt{h+\beta b h^{2}}$ where $b, \tau$, and $h$ are in $\left.\mathrm{mm}\right]$

\begin{tabular}{|c|c|c|c|c|c|c|c|c|c|c|}
\hline \multirow[b]{2}{*}{ Materia] } & \multirow[b]{2}{*}{$\alpha$} & \multirow[b]{2}{*}{$\beta$} & \multicolumn{4}{|c|}{ Standard notch } & \multicolumn{4}{|c|}{ Round notch } \\
\hline & & & $\begin{array}{c}A_{1}= \\
7.05 \alpha\end{array}$ & $\begin{array}{l}A_{2}= \\
640 \beta\end{array}$ & $\begin{array}{c}\text { Calcu- } \\
\text { lated } \\
A=A_{1} \\
+A_{2}\end{array}$ & $\begin{array}{l}\text { Experi- } \\
\text { mental } \\
\text { value } \\
\text { of } A\end{array}$ & $\begin{array}{c}A_{1}= \\
28.2 \alpha\end{array}$ & $\begin{array}{l}A_{2}= \\
640 \beta\end{array}$ & $\begin{array}{c}\text { Calcu- } \\
\text { lated } \\
A=A_{1} \\
+A_{2}\end{array}$ & $\begin{array}{l}\text { Experi- } \\
\text { mental } \\
\text { value } \\
\text { of } A\end{array}$ \\
\hline 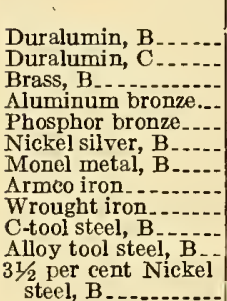 & $\begin{array}{r}0.154 \\
.211 \\
.448 \\
.476 \\
.418 \\
.324 \\
.184 \\
.335 \\
.249 \\
.245 \\
.293 \\
.777\end{array}$ & $\begin{array}{l}0.0169 \\
.0205 \\
.0389 \\
.1084 \\
.0419 \\
.0195 \\
.1996 \\
.0809 \\
.0706 \\
.0016 \\
.0039\end{array}$ & $\begin{array}{r}\text { Ft. }- \text { lb. } \\
1.09 \\
1.49 \\
3.16 \\
3.35 \\
2.95 \\
2.29 \\
1.30 \\
2.36 \\
1.76 \\
1.73 \\
2.07\end{array}$ & $\begin{array}{l}F t .-l b . \\
10.81 \\
13.13 \\
24.88 \\
69.35 \\
26.82 \\
12.48 \\
127.7 \\
51.75 \\
45.15 \\
1.02 \\
2.49\end{array}$ & $\begin{array}{r}F t .-l b . \\
11.90 \\
14.62 \\
28.04 \\
72.70 \\
29.77 \\
14.77 \\
129.0 \\
54.11 \\
46.91 \\
2.75 \\
4.56\end{array}$ & $\begin{aligned} F t .-l b . \\
11.41 \\
14.66 \\
26.26 \\
71.33 \\
27.76 \\
13.81 \\
129.0 \\
53.79 \\
48.89 \\
1.60 \\
3.70\end{aligned}$ & $\begin{array}{r}F t .-l b . \\
4.34 \\
5.95 \\
12.64 \\
13.42 \\
11.80 \\
9.14 \\
5.19 \\
9.45 \\
7.02 \\
6.92 \\
8.26\end{array}$ & $\begin{array}{r}F t .-l b . \\
10.81 \\
13.13 \\
24.88 \\
69.35 \\
26.82 \\
12.48 \\
127.7 \\
51.75 \\
45.15 \\
1.02 \\
2.49\end{array}$ & \begin{tabular}{|r|}
$F t .-l b$. \\
15.15 \\
19.08 \\
37.52 \\
82.77 \\
38.62 \\
21.62 \\
132.89 \\
61.20 \\
52.17 \\
7.94 \\
10.75
\end{tabular} & $\begin{array}{r}F t .-l b . \\
14.68 \\
18.96 \\
33.47 \\
79.40 \\
36.65 \\
17.59 \\
130.50 \\
62.81 \\
52.51 \\
6.8 . \\
8.71\end{array}$ \\
\hline $\begin{array}{l}\text { Average } \\
\text { A verage devia- } \\
\text { tion from the } \\
\text { average of ex- } \\
\text { periment } \\
\text { values......... }\end{array}$ & & & & & $\begin{array}{c}P e t \text { cent } \\
2.9\end{array}$ & 35.6 & & & $\begin{array}{c}\text { Per cent } \\
4.8\end{array}$ & 41.7 \\
\hline
\end{tabular}


TABLE 6.-Coefficients $\alpha$ and $\beta$ determined from values for sharp and deep notches obtained in slow-bend tests and calculated $A_{\mathrm{st}}$ and $A_{\mathrm{r}}$ as compared with experimental slow-bend values

[All values are averages of $A_{\mathrm{t}}$ and $A_{s}$ ]

[ $A=A_{1}+A_{2}=\alpha b r \sqrt{h}+\beta b h^{2}$ where $b, r$, and $h$ are in $\mathrm{mm}$ ]

\begin{tabular}{|c|c|c|c|c|c|c|c|c|c|c|}
\hline \multirow[b]{2}{*}{ Material } & \multirow[b]{2}{*}{$\alpha$} & \multirow[b]{2}{*}{$\beta$} & \multicolumn{4}{|c|}{ Standard notch } & \multicolumn{4}{|c|}{ Round notch } \\
\hline & & & $\begin{array}{c}A_{1}= \\
7.05 \alpha\end{array}$ & $\begin{array}{l}A_{2}= \\
640 B\end{array}$ & $\begin{array}{l}\text { Calcu- } \\
\text { lated } \\
A=A_{1} \\
+A_{2}\end{array}$ & $\begin{array}{c}\text { Experi- } \\
\text { mental } \\
\text { value } \\
\text { of } A\end{array}$ & $\begin{array}{c}A_{1}= \\
28.2 \alpha\end{array}$ & $\begin{array}{l}A_{2}= \\
640 \beta\end{array}$ & $\begin{array}{l}\text { Calcu- } \\
\text { lated } \\
A=A_{1} \\
+A_{2}\end{array}$ & $\begin{array}{l}\text { Experi } \\
\text { mental } \\
\text { value } \\
\text { of } A\end{array}$ \\
\hline 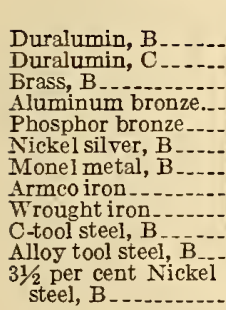 & $\begin{array}{r}0.124 \\
.139 \\
.277 \\
.242 \\
.300 \\
.176 \\
.465 \\
.270 \\
.350 \\
.464 \\
.194 \\
.412\end{array}$ & $\begin{array}{l}0.0079 \\
.0104 \\
.0200 \\
.025 \\
.0219 \\
.0077 \\
.1187 \\
.0750 \\
.0038 \\
.0062 \\
.0039 \\
.0300\end{array}$ & $\begin{array}{r}F t .-7 b . \\
0.87 \\
.98 \\
1.95 \\
1.71 \\
2.11 \\
1.24 \\
3.28 \\
1.90 \\
2.47 \\
3.27 \\
1.37 \\
2.91\end{array}$ & $\begin{array}{r}F t .-l b . \\
5.06 \\
6.66 \\
12.80 \\
65.60 \\
14.01 \\
4.93 \\
75.90 \\
48.00 \\
34.40 \\
3.97 \\
2.49\end{array}$ & $\begin{array}{r}F t .-l b . \\
5.93 \\
7.64 \\
14.75 \\
67.31 \\
16.12 \\
6.17 \\
79.18 \\
49.90 \\
36.87 \\
7.24 \\
3.86 \\
\\
22.11\end{array}$ & $\begin{array}{r}F t .-l b . \\
5.81 \\
8.84 \\
14.05 \\
66.80 \\
16.05 \\
6.42 \\
76.8 \\
49.80 \\
40.10 \\
7.27 \\
4.17 \\
24.29\end{array}$ & $\begin{array}{r}F t .-7 b . \\
3.50 \\
3.92 \\
7.81 \\
6.82 \\
8.46 \\
4.97 \\
13.12 \\
7.62 \\
9.87 \\
13.10 \\
5.47 \\
11.62\end{array}$ & $\begin{array}{r}\text { Ft. } .7 b . \\
5.06 \\
6.66 \\
12.80 \\
65.60 \\
14.01 \\
4.93 \\
75.90 \\
48.00 \\
34.40 \\
3.97 \\
2.49 \\
19.20\end{array}$ & $\begin{array}{r}F t .-l b . \\
8.56 \\
10.58 \\
20.61 \\
72.42 \\
22.47 \\
9.90 \\
89.02 \\
55.62 \\
44.27 \\
17.07 \\
7.96 \\
30.82\end{array}$ & $\begin{array}{r}F t .-l b . \\
9.18 \\
11.37 \\
20.74 \\
74.50 \\
24.17 \\
10.56 \\
83.20 \\
50.30 \\
41.90 \\
22.24 \\
7.71 \\
31.00\end{array}$ \\
\hline $\begin{array}{l}\text { A verage } \\
\text { A verage devia- } \\
\text { tion from the } \\
\text { average of ex- } \\
\text { perimental } \\
\text { values.... }\end{array}$ & & & & & $\begin{array}{c}\text { Per cent } \\
3.4\end{array}$ & 26.7 & & & $\begin{array}{c}\text { Per cent } \\
6.5\end{array}$ & 32.3 \\
\hline
\end{tabular}

In Figure 26 the ratios of $\alpha / \beta$ were plotted against the experimental values of the energy for the "standard" notch. It is evident that for extreme values of the energy the above ratio follows a pretty definite curve. However, for materials of medium toughness the individual values of $\alpha / \beta$ are scattered. An approximate relation between the ratio $\alpha / \beta$ and the energy may be expressed by a number of functions, one of the simplest being $\alpha / \beta=\frac{250}{A_{\mathrm{st}}}$, where $A_{\mathrm{st}}$ is the experimental value of the energy for the "standard" notch. Assuming this relation, the energy for any notch may be expressed directly in the terms of that for the "standard" notch. After the necessary transformations we have

$$
A=A_{1}+A_{2}=\frac{b r \sqrt{h} \times A_{\mathrm{st}}}{7.05+2.56 A_{\mathrm{st}}}+\frac{b h^{2} A^{2}{ }_{\mathrm{st}}}{1765+640 A_{\mathrm{st}}}
$$

In Table 7 are found the values of $A$ for the deep notch, which were computed according to formula (3). 
TABLE 7.-Values of energy for deep and round notches in impact test, calculated from those for standard notch, according to formula

$$
A=A_{1}+A_{2}=\frac{b r \sqrt{h \times} A_{\mathrm{at}}}{7.05+2.56 A_{\mathrm{at}}}+\frac{b h^{2} \times A^{2} \mathrm{at}}{1765+640 A_{\mathrm{at}}}
$$

\begin{tabular}{|c|c|c|c|c|c|c|c|c|}
\hline \multirow[b]{2}{*}{ Material } & \multicolumn{4}{|c|}{ Round notch } & \multicolumn{4}{|c|}{ Deep notch } \\
\hline & $A_{1}$ & $A_{2}$ & $\begin{array}{c}\text { Calcu- } \\
\text { lated } \\
A= \\
A_{1}+A_{2}\end{array}$ & $\begin{array}{l}\text { Experi- } \\
\text { mental } \\
\text { value } \\
\text { of } A\end{array}$ & $A_{1}$ & $A_{2}$ & $\begin{array}{c}\text { Calcu- } \\
\text { lated } \\
A= \\
A_{1}+A_{2}\end{array}$ & $\begin{array}{l}\text { Experi- } \\
\text { mental } \\
\text { value } \\
\text { of } A\end{array}$ \\
\hline $\begin{array}{l}\text { Duralumin, B } \\
\text { Duralumin, C. } \\
\text { Brass, B .. } \\
\text { Aluminum bronze } \\
\text { Phosphor bronze } \\
\text { Nickel silver, B } \\
\text { Monel metal, B B } \\
\text { Armeo iron } \\
\text { Wrought iron } \\
\text { C-tool steel, B } \\
\text { Alloy tool steel, B } \\
\text { 31\%2 per cent nickel steel, B }\end{array}$ & $\begin{aligned} F t .-l b . \\
8.88 \\
9.28 \\
10.00 \\
10.62 \\
10.04 \\
9.19 \\
10.80 \\
10.50 \\
10.45 \\
9.40 \\
6.32 \\
9.92\end{aligned}$ & $\begin{array}{r}F t .-l b . \\
9.18 \\
12.34 \\
23.86 \\
68.70 \\
25.28 \\
11.54 \\
126.40 \\
51.20 \\
46.20 \\
.59 \\
2.12 \\
22.65\end{array}$ & $\begin{array}{r}F t .-l b . \\
18.06 \\
21.62 \\
33.86 \\
79.32 \\
35.32 \\
20.73 \\
137.20 \\
61.70 \\
56.65 \\
9.99 \\
8.44 \\
32.57\end{array}$ & $\begin{aligned} F t . . l b . \\
14.68 \\
18.96 \\
33.47 \\
79.40 \\
36.65 \\
17.59 \\
130.50 \\
62.81 \\
52.51 \\
6.84 \\
8.71 \\
37.67\end{aligned}$ & $\begin{array}{l}F t .-l b . \\
7.00 \\
7.30 \\
7.88 \\
8.37 \\
7.90 \\
7.82 \\
8.50 \\
8.27 \\
8.23 \\
3.19 \\
4.98 \\
7.83\end{array}$ & $\begin{aligned} F t .-2 b . \\
. .59 \\
4.92 \\
9.28 \\
27.32 \\
9.85 \\
4.50 \\
40.80 \\
19.95 \\
18.08 \\
.23 \\
.63 \\
8.77\end{aligned}$ & $\begin{array}{r}F t .-l b . \\
10.59 \\
12.22 \\
17.16 \\
35.69 \\
17.75 \\
12.32 \\
49.30 \\
28.22 \\
26.31 \\
3.42 \\
5.61 \\
16.60\end{array}$ & $\begin{aligned} F t .-l b . \\
7.71 \\
9.87 \\
19.81 \\
37.84 \\
19.86 \\
12.16 \\
54.07 \\
27.77 \\
23.74 \\
5.88 \\
7.51 \\
24.64\end{aligned}$ \\
\hline $\begin{array}{l}\text { A verage deviation from the aver- } \\
\text { age of experimental values..... }\end{array}$ & & 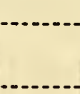 & $\left|\begin{array}{c}43.0 \\
\text { Per cent } \\
6.3\end{array}\right|$ & 41.7 & & & $\left|\begin{array}{c}19.6 \\
P e r c e n t \\
13.0\end{array}\right|$ & 20.9 \\
\hline
\end{tabular}

Comparing the calculated values of the impact energy for the "round" notch obtained by means of coefficients $\alpha$ and $\beta$, $A=\alpha b r \sqrt{h}+\beta b h^{2}$ and the same values calculated by formula

$$
A=\frac{b r \sqrt{h} \times A_{\mathrm{st}}}{7.05+2.56 A_{\mathrm{st}}}+\frac{b h^{2} \times A^{2} \mathrm{st}}{1765+640 A_{\mathrm{st}}}
$$

it is evident that the second terms agree fairly well. The first terms show greater discrepancies, which make the determination of $A$, from its value for one notch only, less reliable than from the values for two different notches.

\section{CONCLUSIONS}

\section{MACHINE}

(a) A notched bar test in the slow-bend machine requires more care from the operator than an impact test, and the machine itself is more likely to get out of order than an impact machine.

(b) The slow-bend values for specimens of tough materials which do not break are not directly comparable with the impact values, because the angle of bend is different for the two machines. Although the reduction of the slow-bend values to the same angle of bend is only approximate, in most cases the approximation is sufficiently accurate for practical purposes.

(c) The slow-bend values have a number of errors, some of which, at least, ought to be corrected, the corrections being of an approxi- 
mate nature. The sum of all the errors in a slow bend is, however, of about the same magnitude as in an impact machine.

(d) In addition to a value of absorbed energy, the slow-bend test gives other information regarding the manner in which the energy is absorbed, which is not easily obtainable in an impact test; such, for instance, as the bending moment corresponding to any angle of bend.

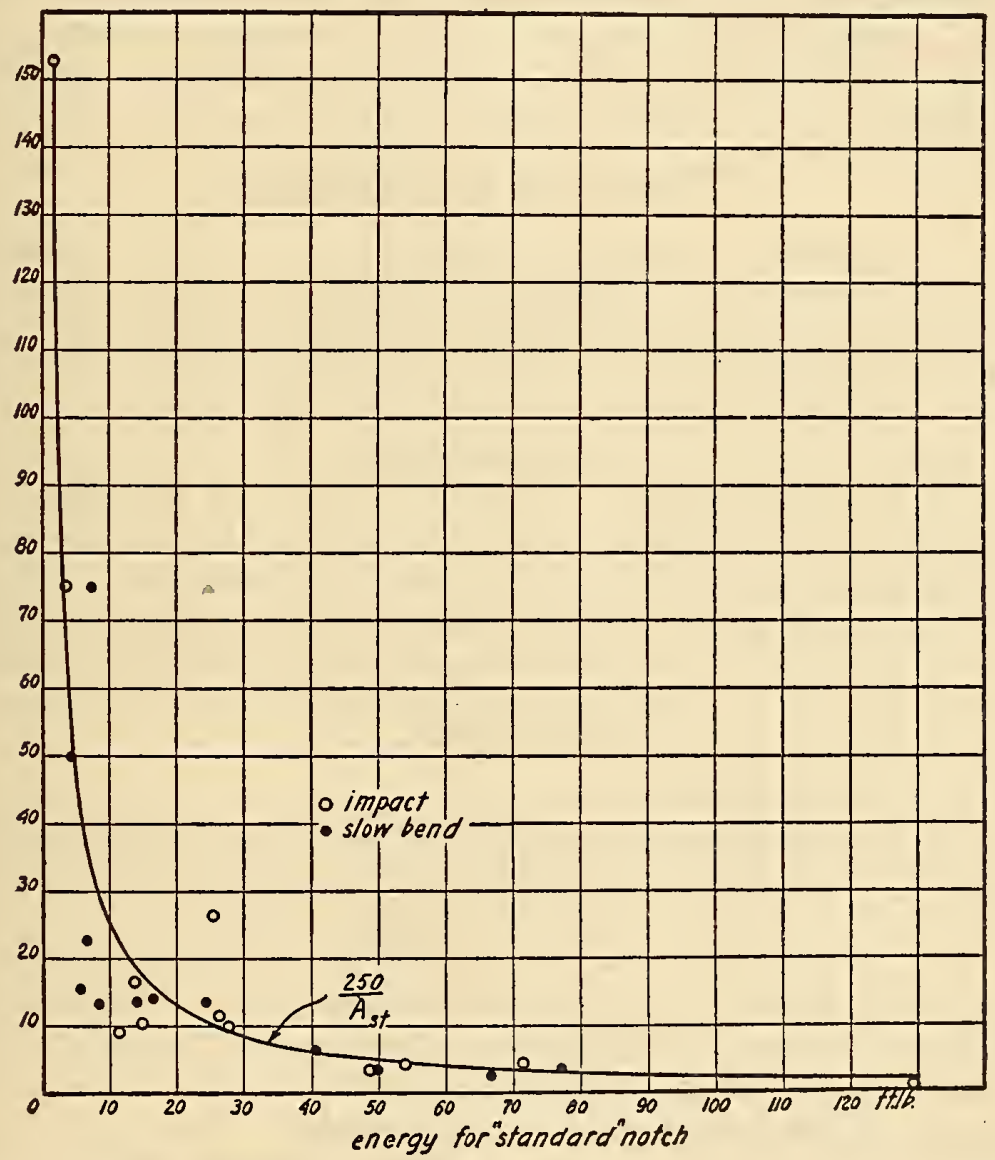

FIG. 26.-Relation between the coefficients $\alpha$ and $\beta$ in the formula $A=\alpha b r \sqrt{h}+\beta h^{2}$

\section{EFFECT OF SPEED}

(a) Usually the slow-bend method gives lower values for the nonferrous materials and higher ralues for steels than does the impact method. The slow bend shows less difference between the tough and brittle materials than does the impact method.

(b) The slow-bend and the impact values for nonferrous materials are fairly comparable among themselves. This relation is not as close for the ferrous materials. 
(c) There is no well-defined relation between the impact or the slow-bend values and the other properties of materials. Some values, however, which are obtained in a slow-bend test are correlated with the tensile test values. Thus, the bending moment given by a slowbend diagram is in a pretty close relationship to the tensile strength and to the yield point for practically all tested materials.

(d) Both methods are about equally reliable in detecting the differences in the notched-bar values which may be present for the specimens cut from the same bar or for the specimens having the notches differently placed in respect to the rolling direction.

\section{FRACTURE OF SPECIMEN}

(a) The notched-bar test, and particularly the notched bar impact test, is very sensitive in showing up the directional differences in the properties of rolled metals caused by their fibrous structure and may be more conveniently used for this purpose than other tests. This refers to the specimens cut in the direction of rolling, as all the materials used in this investigation were in the shape of flat bars.

(b) When the notched-bar values are given in a specification or otherwise, mention should be made of the location of the notch relative to the plane of rolling and to the rolling direction.

(c) The variation in the individual values of notched-bar tests made on the same sample and under identical conditions can, in a good many cases, be directly accounted for by the structural condition of metal instead of being considered as test errors which are beyond the control of operator.

(d) It is evident that the notched-bar impact test may be used as a convenient method to measure the weakening effect of inclusions where other tests would be more costly or less conclusive.

(e) The metals here tested were comparatively "clean," and no general conclusions are being made in respect to the "dirtiness" of metals and its effect on toughness. This question, however, seems to deserve further study, with the purpose of using the impact test as a sensitive method of detecting "dirty" metals.

\section{NOTCH}

(a) For both the slow bend and the impact tests the energy increases linearly with the increase of the radius of notch if the depth of the notch is constant.

(b) For both the slow bend and the impact tests on tough materials the energy increases rapidly with the increase of the net thickness of the specimen. For brittle materials the effect of the net thickness is comparatively small.

(c) The "sharp," "standard," and "round" notches place materials in the same relative order for their resistance to impact or to 
slow bena. For brittle materials the "sharp" and the "standard" notches are preferable, because the notched-bar values for such materials are more responsive to the effect of the radius of notch.

(d) The "deep" notch is not as good as the other three notches which were used in this work. The smaller net thickness of the specimen having this notch is responsible for the lower values for tough materials, which are greatly affected by the net thickness, while the values for the specimens from brittle materials are comparatively little affected by the net thickness. On the other hand, the absence of a sharp angle at the bottom of this notch tends to give comparatively high values for brittle materials, thus making the extreme differences less pronounced.

\section{EMPIRICAL FORMULA}

(a) The energy absorbed in an impact or in a slow-bend test may be expressed by the equation

$$
A=\alpha b r \sqrt{h}+\beta b h^{2}
$$

in which $\alpha$ and $\beta$ are constants for a given material; $b, r$, and $h$ are the width of specimen, the radius of notch, and the net thickness of specimen, respectively. Constants $\alpha$ and $\beta$ may be found by determining energy for two different notches.

\section{BIBLIOGRAPHY}

A list of works on impact testing will be found in Proc. Am. Soc. Test. Mat. Part II, 1922, p. 9. It gives, also, a chronological and a subject index. In addition to this, a list of works which were published in 1922 and later is given below.

Anonymous.

Deformation of material by impact test. Chem. and Metal. Eng., October $11,1922$.

Significance of notched bar impact test. Eng., December 28, 1923.

Bultman-Izod impact testing machine. Am. Mach., May 3, 1923.

Photorecording extensometer for impact test. Eng. N. Rec., March 22, 1923.

Pittsburgh impact testing machine. Am. Mach., November 1, 1923.

Brittleness. The Metal Industry, London, February 15, 1924, p. 151.

BEAN, W. R.

Effects of hot dip galvanizing on notched bar test. Foundry, June 1, 1923.

Bunting, D.

Brittleness in Brass. Eng., March 14, 1924, p. 350.

DURRER, R.

Discusses the application of Dr. P. Fillunger's formula. Stahl und Eisen, No. 4, 1919, p. 99.

Elmendorf, A.

Measuring forces in impact. Proc. A. S. T. M., 1922, p. 117. 
Fillunger, P.

Gives formula expressing the relation between the dimensions of specimen and notch and the impact value. Zeitschrift d. V. Oesterr. Ing. und Arch. Ver., 1918, No. 30. Also "Testing," No. 1, 1924, p. 23.

Greaves, R. H., and Moore, F.

Effect of the form of test piece and of machine on impact value. Proc. Inst. Civ. Eng., 1920-21, p. 101.

Effect of overstrain on impact value of steel. Proc. Inst. Civ. Eng., 1920-21, p. 120.

HADFIELD, R. A.

Standardization of shock test. Proc. Inst. Civ. Eng., 1920-21, p. 127.

HoLz, H. A.

Recent researches on static notc hed-bar testing. Chem. and Metal Eng. May 17, 1922.

Impact properties of various steels. Chem. and Metal. Eng., November 16, 1921.

Effect of temperature on impact resistance of steel. Iron Age, November 1, 1923.

Significance of impact test. Proc. A. S. T. M., 1922, p. 128.

LESSELS, J. M.

Impact testing. Soc. Auto. Eng. Jour., January, 1923.

Lodwik, P., and Sched, R.

Notched-bar test of mild steel. Stahl und Eisen, August 2, 1923.

LyNCH, T. D.

Review of work on impact test in Great Britain. Proc. A. S. T. M., 1922, p. 100.

MARGERUM, C. E.

Measurement of impact pressures. Proc. A. S. T. M., 1922, p. 104.

Matsomora, T.

Effect of depth of notch. Soc. Mech. Eng. of Tokyo, Japan, June, 1922, p. 73.

MOORE, H. F.

Measuring force of impact. Proc. A. S. T. M., 1922, p. 124.

Moser, M.

What is the notched-bar test? Stahl und Eisen, July 19, 1923.

Effect of dimensions of test piece on impact value. Stahl und Eisen, pp. 90 and $1055 ; 1922$.

Richardson, N., and MacNutt, E.

Effect of temperature on impact resistance of steel. Trans. Am. Soc. for Steel Treating, April, 1924, p. 348.

Sмiтh, E. B.

Accelerometer for measuring impact. Eng. News-Record, July 5, 1923.

Stribeck, R.

The unexplored notched-bar test. Stahl und Eisen, March 16, 1922.

WARWICK, C. L.

Résumé of American practice in notched-bar impact test. Proc. A. S. T. M., 1922 , p. 78.

WELTER, G.

Shock elastioity of metals and alloys. Zeitschr. für Metallkunde, January, 1924 , p. 6.

Washington, November 14, 1924. 